\title{
Stable isotope probing and metagenomics highlight the effect of plants on uncultured phenanthrene-degrading bacterial consortium in polluted soil
}

\author{
François Thomas $\mathbb{1}^{1,2} \cdot$ Erwan Corre $^{3} \cdot$ Aurélie Cébron $\mathbb{C}^{1}$
}

Received: 23 August 2018 / Revised: 8 February 2019 / Accepted: 28 February 2019 / Published online: 14 March 2019

(c) International Society for Microbial Ecology 2019

\begin{abstract}
Polycyclic aromatic hydrocarbons (PAHs) are ubiquitous soil pollutants. The discovery that plants can stimulate microbial degradation of PAHs has promoted research on rhizoremediation strategies. We combined DNA-SIP with metagenomics to assess the influence of plants on the identity and metabolic functions of active PAH-degrading bacteria in contaminated soil, using phenanthrene (PHE) as a model hydrocarbon. ${ }^{13} \mathrm{C}$-PHE dissipation was 2.5 -fold lower in ryegrass-planted conditions than in bare soil. Metabarcoding of $16 \mathrm{~S}$ rDNA revealed significantly enriched OTUs in ${ }^{13} \mathrm{C}$ SIP incubations compared to ${ }^{12} \mathrm{C}$-controls, namely 130 OTUs from bare soil and 73 OTUs from planted soil. Active PHE-degraders were taxonomically diverse (Proteobacteria, Actinobacteria and Firmicutes), with Sphingomonas and Sphingobium dominating in bare and planted soil, respectively. Plant root exudates favored the development of PHEdegraders having specific functional traits at the genome level. Indeed, metagenomes of ${ }^{13} \mathrm{C}$-enriched DNA fractions contained more genes involved in aromatic compound metabolism in bare soil, whereas carbohydrate catabolism genes were more abundant in planted soil. Functional gene annotation allowed reconstruction of complete pathways with several routes for PHE catabolism. Sphingomonadales were the major taxa performing the first steps of PHE degradation in both conditions, suggesting their critical role to initiate in situ PAH remediation. Active PHE-degraders act in a consortium, whereby complete PHE mineralization is achieved through the combined activity of taxonomically diverse co-occurring bacteria performing successive metabolic steps. Our study reveals hitherto underestimated functional interactions for full microbial detoxification in contaminated soils.
\end{abstract}

\section{Introduction}

Polycyclic aromatic hydrocarbons (PAHs) are ubiquitous soil pollutants with environmental and public health concerns [1]. PAHs released into the environment by

Supplementary information The online version of this article (https:// doi.org/10.1038/s41396-019-0394-z) contains supplementary material, which is available to authorized users.

Aurélie Cébron

aurelie.cebron@univ-lorraine.fr

1 Université de Lorraine, CNRS, LIEC, 54500 Nancy, France

2 Sorbonne Université, CNRS, Integrative Biology of Marine Models (LBI2M), Station Biologique de Roscoff (SBR), 29680 Roscoff, France

3 CNRS, Sorbonne Université, FR2424, ABiMS, Station Biologique de Roscoff, 29680 Roscoff, France industrial activities can be removed through physical, chemical, and biological processes [2]. Microorganisms that use PAHs as carbon sources play essential roles in natural attenuation of pollutants in contaminated ecosystems [3]. Numerous PAH catabolic pathways are described in bacteria, archaea, and fungi, including both aerobic and anaerobic processes [1,3]. Several studies have evidenced an increased microbial degradation of PAHs in the presence of plants $[4,5]$. The discovery of this "rhizosphere effect" has promoted the development of rhizoremediation strategies to treat PAH-contaminated soils [6, 7]. However, the literature shows conflicting results with no rhizosphere effect or even a negative influence on PAH-degradation efficiency [8,9]. These discrepancies may reflect the use of different model plants, soil types, indigenous microorganisms [10], and types of PAHs [11]. Such variations may also result from temporal variations in rhizospheric processes during plant development, whose determinants 
must be identified to better control rhizoremediation processes.

We previously showed that phenanthrene degradation was slowed down during the early development of ryegrass [12], a plant commonly used in PAH rhizoremediation studies [13]. Differences in PAH degradation with or without plants could be explained by the selection of two distinct PAH-degrading bacterial populations. Indeed, active bacterial populations were different in soil supplemented or not with root exudates [14] and in planted or bare soil microcosms [12]. Plant roots exude labile carbon sources that can be preferentially degraded by rhizospheric microbial communities to the detriment of PAH dissipation [9]. Therefore, investigation of PAHdegraders in the rhizosphere of contaminated soils is needed to decipher the influence of plants and ultimately improve PAH biodegradation efficiency.

One challenge is to specifically target microorganisms actively degrading PAHs in polluted soils without cultivation bias. DNA-stable isotope probing (DNA-SIP) is a powerful technique for linking functions with identity of uncultured microorganisms in complex microbiota. Approaches combining DNA-SIP and metagenomics are increasingly used to investigate microbial communities involved in anthropogenic compound biodegradation [1517]. To date DNA-SIP has been successfully applied to identify soil bacteria that metabolize PAHs such as naphthalene [18-21], phenanthrene [14, 19, 22-27], anthracene [25, 28, 29], fluoranthene [25], pyrene [30, 31], and benzo[a]pyrene [32]. DNA-SIP has also been used to explore PAH-degraders in the presence of purified root exudates [14] and to identify degraders of root exudates in the rhizosphere [33]. However, we still lack a comprehensive view on the major microbial actors of PAH degradation and their catabolic pathways in contaminated soils, and how it changes in the presence of plants [34].

In this study, we investigated PAH-degrading bacteria of a historically polluted soil, using ${ }^{13} \mathrm{C}$-labeled phenanthrene (PHE) as a metabolic tracer. We combined DNASIP with metagenomics to assess for the first time the influence of plant rhizosphere on the diversity, identity, and metabolic functions of bacteria actively involved in phenanthrene degradation. Our objectives were to determine the diversity and metabolic properties of active soil PAH-degrading bacteria both in bare and planted soils. We hypothesized first that plants would select for contrasting PAH-degrading bacteria with altered PAHbiodegradation pathways leading to an increase in biodegradation efficiency in the rhizosphere. Second, we hypothesized that the PAH-degrading microbial guild is composed of diverse bacteria possessing complete catabolic pathways and acting in parallel.

\section{Material and methods}

\section{Soil sample and phenanthrene spiking}

Soil was collected from a former coking plant site (NM soil, Neuves-Maisons, France), dried at room temperature, sieved to $2 \mathrm{~mm}$ and stored in the dark at room temperature until experimental set-up. PAH contamination dates back ca. 100 years and reaches $1260 \mathrm{mg} \mathrm{kg}^{-1}$ (sum of the 16 US-EPA PAHs) with $7 \%$ of phenanthrene $\left(90 \mathrm{mg} \mathrm{kg}^{-1}\right)$. Other soil characteristics were detailed elsewhere [35]. For spiking, two batches of soil were recontaminated at $2500 \mathrm{mg} \mathrm{kg}^{-1}$ respectively with $\left[\mathrm{U}^{13} \mathrm{C}_{14}\right]$-labeled phenanthrene (SigmaAldrich Isotec, St Louis, USA) and unlabeled ${ }^{12} \mathrm{C}-\mathrm{PHE}$ (Fluka). Ten grams of dry soil were mixed with $2.5 \mathrm{ml}$ of PHE stock solutions (10 $\mathrm{mg} \mathrm{ml}^{-1}$ in hexane). After complete solvent evaporation ( $48 \mathrm{~h}$ under a fumehood), aliquots of $1.1 \mathrm{~g}$ recontaminated soil were mixed with $9.9 \mathrm{~g}$ of nonrecontaminated soil (1:10 dilution) to obtain a final concentration of fresh PHE of $250 \mathrm{mg} \mathrm{kg}^{-1}$. This spiked-soil was immediately used for SIP incubations.

\section{SIP incubations}

SIP incubations were performed using previously described two-compartment microcosms [12]. Eight ryegrass seedlings (Lolium multiflorum, Italian ryegrass, Podium variety, LG seeds, France) were allowed to grow for 21 days until roots reached the bottom of the first compartment containing $30 \mathrm{~g}$ of non-recontaminated NM soil and maintained at $80 \%$ of the soil water-holding capacity in a growth chamber $\left(22 / 18{ }^{\circ} \mathrm{C}\right.$ day/night, $80 \%$ relative humidity, c.a. $250 \mu \mathrm{mol}$ photons $\mathrm{m}^{-2} \mathrm{~s}^{-1}, 16 \mathrm{~h}$ photoperiod). A second compartment containing $10 \mathrm{~g}$ of ${ }^{12} \mathrm{C}$ or ${ }^{13} \mathrm{C}$ PHE-spiked soil, moistened at $80 \%$ of the soil water-holding capacity, was then appended below the first one to allow root colonization in the growth chamber. After 10 days, soil from the second compartment was retrieved in a glass Petri dish. Roots were removed using a brush and tweezers. Aliquots of soil were collected in glass vials for organic extraction and isotopic analysis; the rest was stored in plastic vial and immediately frozen in liquid nitrogen for further nucleic acid extraction. All samples were stored at $-80{ }^{\circ} \mathrm{C}$ until analysis. Nonvegetated ("bare") microcosms were handled in the same way, except no ryegrass was planted in the first compartment. Independent triplicates were performed for the four conditions (i.e. ${ }^{12} \mathrm{C}$-bare, ${ }^{12} \mathrm{C}$-planted, ${ }^{13} \mathrm{C}$-bare, and ${ }^{13} \mathrm{C}$ planted), for a total of 12 microcosms. Aerial plant biomass was harvested, ground in liquid nitrogen, dried at $60^{\circ} \mathrm{C}$, and stored at room temperature. To capture the initial PHE concentration, an additional set of second compartments was prepared and killed within $2 \mathrm{~h}$. 
Organic extraction and phenanthrene quantification

Lyophilized soil was pulverized in a mixer mill (MM200, Retsch). Soil samples $(250 \mathrm{mg}$ ) were mixed with $1 \mathrm{~g}$ activated copper and $2 \mathrm{~g}$ anhydrous $\mathrm{Na}_{2} \mathrm{SO}_{4}$ and extracted with dichloromethane (DCM) using an high pressure and temperature automated extractor Dionex ASE350 as described elsewhere [36]. Post-extraction soil residues were recovered for isotopic analysis. DCM extracts were analyzed by gas chromatography coupled to mass spectrometry (GC-MS) to quantify ${ }^{13} \mathrm{C}$-PHE concentration [37]. The ${ }^{13} \mathrm{C}$ content (coming from the added ${ }^{13} \mathrm{C}$-PHE) was deduced from these data, using the formula: ${ }^{13} \mathrm{C}_{\text {sample }}=\alpha \times \mathrm{PHE}_{\text {sample, }}$, where $\mathrm{PHE}_{\text {sample }}$ is the ${ }^{13} \mathrm{C}-\mathrm{PHE}$ content $\left(\mathrm{mg} \mathrm{kg}^{-1}\right)$ and $\alpha$ the massic proportion of carbon atoms in PHE molecule (0.9434). The proportion of ${ }^{13} \mathrm{C}$ remaining compared to the amount added initially was expressed as $100 \times{ }^{3} \mathrm{C}_{\text {sample } \mathrm{D} 10} /$ ${ }^{13} \mathrm{C}_{\text {sample D0 }}$. D0 was the initial measure and D10 after 10 days.

\section{Isotopic analysis}

Isotopic composition of soil samples and post-extraction soil residues, dry DCM extracts, and aerial plant biomass was determined at the INRA PTEF (Champenoux, France) using Elemental analyzer (vario ISOTOPE cube, Elementar, Hanau, Germany) interfaced in line with a gas isotope ratio mass spectrometer (IsoPrime 100, Isoprime Ltd, Cheadle, UK). Carbon isotopic composition was expressed as $\delta^{13} \mathrm{C}$ $(\% o)$ versus Vienna PeeDee Belemnite (V-PDB). The ratio of ${ }^{13} \mathrm{C}$ versus ${ }^{12} \mathrm{C}$ in samples was expressed as $R_{\text {sample }}=$ $R_{\mathrm{V}-\mathrm{PDB}} \times\left(1+\delta^{13} \mathrm{C}_{\text {sample }} / 1000\right)$, where $R_{\mathrm{V}-\mathrm{PDB}}={ }^{13} \mathrm{C}_{\mathrm{V}-\mathrm{PDB}} /$ ${ }^{12} \mathrm{C}_{\mathrm{V} \text {-PDB }}=0.0112375$. The proportion of ${ }^{13} \mathrm{C}$ in a sample compared to the amount initially added from ${ }^{13} \mathrm{C}$-PHE was calculated as $\left(R_{\text {sample D10 }}-R_{\text {matrix }}\right) /\left(R_{\text {sample D0 }}-R_{\text {matrix }}\right)$, where $R_{\text {matrix }}$ is the natural ${ }^{13} \mathrm{C} /{ }^{12} \mathrm{C}$ ratio of the $\mathrm{NM}$ soil, DCM extracts or soil residues (average 0.01085).

\section{DNA extraction and isopycnic separation}

DNA was extracted from $0.5 \mathrm{~g}$ of soil using the Fast DNA Spin Kit for Soil (MP Biomedicals, France). Five replicate extractions were pooled for each sample. DNA was quantified using the Quant-iT Picogreen dsDNA assay kit (Invitrogen). Isopycnic separation of ${ }^{12} \mathrm{C}$ - and ${ }^{13} \mathrm{C}$-labeled DNA ("light" and "heavy" DNA, respectively) was performed as described previously [38]. DNA $(3.9 \mu \mathrm{g})$ was mixed in $5.1 \mathrm{ml}$ tubes with $\mathrm{CsCl}$ solution and gradient buffer to a final density of $1.725 \mathrm{~g} \mathrm{ml}^{-1}$. Ultracentrifugation was performed in a vertical rotor (VTi 65.2, Beckman), at $15^{\circ} \mathrm{C}, 176985 \times g$ for $40 \mathrm{~h}$ (INRA, Champenoux). Thirteen fractions (ca. $400 \mu \mathrm{l}$ ) were collected per tube and weighed on a digital balance (precision $10^{-4} \mathrm{~g}$ ) to confirm gradient formation. DNA was precipitated with $800 \mu$ l polyethylene glycol $6000(1.6 \mathrm{M})$ and $2 \mu$ polyacryl carrier (Euromedex) overnight at room temperature, recovered by centrifugation $45 \mathrm{~min}$ at $13,000 \times g$ and washed once with $500 \mu \mathrm{l} 70 \%(\mathrm{v} / \mathrm{v})$ ethanol. Pellets were dried for $2 \mathrm{~min}$ in a vacuum concentrator (Centrivap Jouan RC1010, ThermoScientific), resuspended in $30 \mu \mathrm{l}$ molecular-biology grade water (Gibco, Life Technologies) and stored at $-20^{\circ} \mathrm{C}$.

\section{Real-time quantitative PCR}

Bacterial 16S, Archaeal 16S, and fungal 18S rRNA gene copies were quantified using the primer pairs $968 \mathrm{~F} / 1401 \mathrm{R}$ [39], 571F/910R [40], and FF390R/Fung5F [41, 42]. Realtime quantitative PCR (qPCR) reactions $(20 \mu \mathrm{l})$ were performed as described previously [43] on a CFX96 real-time system (BioRad) and contained 1X iQ SybrGreen Super Mix (BioRad), $12 \mu \mathrm{g}$ bovine serum albumin, $0.2 \mu$ dimethyl sulfoxide, $40 \mu \mathrm{g}$ of $\mathrm{T} 4$ bacteriophage gene 32 product (MP Biomedicals, France), $1 \mu \mathrm{l}$ of template (DNA or 10-fold linearized standard plasmid dilution series from $10^{8}$ to $10^{2}$ gene copies per $\mu \mathrm{l}^{1}$ ) and 8 pmol of each primer. Reactions were heated at $95^{\circ} \mathrm{C}$ for $5 \mathrm{~min}$, followed by 45 cycles of $30 \mathrm{~s}$ at $95^{\circ} \mathrm{C}, 30 \mathrm{~s}$ at $56^{\circ} \mathrm{C}$ for bacterial $16 \mathrm{~S}$ rRNA, $60^{\circ} \mathrm{C}$ for archaeal $16 \mathrm{~S}$ rRNA or $50^{\circ} \mathrm{C}$ for $18 \mathrm{~S}$ rRNA, $30 \mathrm{~s}$ at $72^{\circ}$ $\mathrm{C}$ and $10 \mathrm{~s}$ at $82^{\circ} \mathrm{C}$ to capture the fluorescence signal while dissociating primer dimers. Dissociation curves were obtained by heating reactions from 50 to $95^{\circ} \mathrm{C}$. Fractions identified as containing "heavy" DNA (fractions 8, 7, and 6 with buoyant density from 1.713 to $1.727 \mathrm{~g} \mathrm{ml}^{-1}$ ) were pooled and quantified by Picogreen assay.

\section{S rRNA gene amplicon sequencing and analysis}

Fragments of $430 \mathrm{bp}$ covering the V3/V4 region of bacterial $16 \mathrm{~S}$ rRNA genes were amplified from 12 samples of "heavy" DNA (pool of fractions 6-8) recovered from ${ }^{13} \mathrm{C}$ $\mathrm{SIP}$ and ${ }^{12} \mathrm{C}$-control samples and sequenced as described previously [12] with a dual-index paired-end strategy [44]. Amplicons were obtained by 28 cycles of PCR using Accuprime Super Mix (Invitrogen) on $1 \mu$ template DNA, purified using the UltraClean-htp 96 Well PCR Clean-Up kit (MOBIO) and quantified by Picogreen assay. An equimolar pool at $10 \mathrm{nM}$ was purified using Nucleospin PCR Clean-Up kit (Macherey-Nagel) and sequenced on a single lane of Illumina Miseq PE250 at the Georgia Genomics Facility (Athens, GA, USA). Paired-end reads were trimmed to a minimum Qscore of 20, joined with Pandaseq [45] and filtered for length in the $400-450 \mathrm{bp}$ range with no ambiguous bases. Sequence data were analyzed as described previously [12] in QIIME v1.9 [46] with chimera detection and clustering in Operational Taxonomic Units (OTUs) at 97\% using UCHIME and USEARCH v6.1, 
respectively [47, 48], followed by taxonomy assignment using the RDP classifier [49] with the Greengenes database v13_8 [50]. After removal of chloroplasts and mitochondria OTUs, datasets were rarefied to the lowest number of sequences per sample (9532 sequences). To identify ${ }^{13} \mathrm{C}$ labeled OTUs, we used an analytical approach that falls into the Method 2 of the "Heavy-SIP" category [51], whereby labeled taxa were identified as OTUs present in the "heavy" fractions of the ${ }^{13} \mathrm{C}$-SIP treatment and at a significantly lower abundance or absent in "heavy" fractions of the ${ }^{12} \mathrm{C}$ control treatment. To this end, a subset of data were produced to keep only OTUs (i) represented by at least 5 sequences in each triplicate ${ }^{13} \mathrm{C}$-SIP sample and (ii) with an average abundance higher in ${ }^{13} \mathrm{C}$-SIP samples compared to ${ }^{12} \mathrm{C}$-controls. This subset was then log-transformed and compared using Welch's test with Benjamini-Hochberg correction of the $p$-value performed in $\mathrm{R}$ v3.1.3 [52], separately for bare and planted samples.

\section{Shotgun metagenomic sequencing and analysis}

"Heavy" DNA recovered from the six ${ }^{13} \mathrm{C}-\mathrm{SIP}$ samples was sequenced on 3 lanes of Illumina MiSeq PE300 at the Georgia Genomics Facility (Athens, GA, USA). Adapters removal and quality filtering was performed on raw reads using Trimmomatic v0.33 [53] with the following parameters: remove adapters (ILLUMINACLIP:adapters. fa:2:30:10), trim 5'- or 3'-bases if phred Qscore $<25$ (LEADING:25 TRAILING:25), trim read when average quality <25 (SLIDINGWINDOW:4:25) and discard reads shorter than $100 \mathrm{bp}$ (MINLEN:100). Based on FastQC report, paired and unpaired reads 2 obtained after Trimmomatic were further cropped at 250 and $230 \mathrm{bp}$, respectively. Unassembled DNA sequences were uploaded to MG-RAST [54] and compared to the Subsystems database (November 2017) with default parameters. Proportions in functional profiles were compared using Welch's two-sided test with Benjamini-Hochberg correction. Raw metagenomic reads were assembled separately for each sample using SPAdes v3.7.0 [55], with the -meta option and testing kmer sizes of 21, 33, 55, 77, 99 and 127. Taxonomic assignment of assembled contigs longer than $5 \mathrm{~kb}$ was performed using PhyloPythias [56]. Genomic features on assembled contigs were predicted and annotated using prokka v1.12 [57]. Predicted genomic features were also screened for functional genes encoding enzymes potentially involved in aerobic degradation of aromatic compounds using AromaDeg [58], with minimum BLAST homology of $50 \%$ and minimum alignment length of $150 \mathrm{bp}$. Sequences of selected AromaDeg enzyme families were further aligned using MAFFT [59] with the L-INS-i method. Alignments were manually edited in JalView [60] and used for maximum-likelihood phylogenetic tree construction in
MEGA v6 [61] after selection of the best protein model. Genes encoding putative carbohydrate active enzymes (CAZymes) were annotated using dbcan [62]. The GhostKOALA annotation server [63] was used to assign KEGG orthologies to genes in the metagenomes and reconstruct metabolic pathways.

\section{Data access}

16S rRNA gene amplicon sequences are available at NCBI under BioProject ID PRJNA485442 (BioSamples: SAMN09791490-SAMN09791501). Raw and assembled shotgun metagenomics data are available on MG-RAST under study name RHIZORG_WGS and RHIZORG_ASSEMBLED, respectively.

\section{Results}

\section{Fate of phenanthrene}

The fate of spiked PHE was followed in total soil, organic extracts, and soil residues after extraction using both $\delta{ }^{13} \mathrm{C}$ analyses (AE-IRMS) and direct ${ }^{13} \mathrm{C}$-PHE measurements (GC-MS) (Table 1). No significant decrease in ${ }^{13} \mathrm{C}$ content was observed in total soil over the 10-day period, indicating no/low ${ }^{13} \mathrm{C}_{-} \mathrm{CO}_{2}$ loss through mineralization. The proportion of ${ }^{13} \mathrm{C}$ remaining in DCM extracts (containing PAHs and thus ${ }^{13} \mathrm{C}$-PHE) decreased ca. $25 \%$ in bare soil and only $10 \%$ in planted soil (Welch t-test $P=0.06$ ). Consistency between AE-IRMS and GC-MS results indicates that most of the DCM-extractable ${ }^{13} \mathrm{C}$ was ${ }^{13} \mathrm{C}$-PHE, without major contributions of ${ }^{13} \mathrm{C}$-labeled degradation by-products/metabolites. At day $0,3.5 \%$ of the spiked ${ }^{13} \mathrm{C}$ was already nonextractable with DCM and recovered in soil residues, suggesting a rapid sequestration of PHE on soil particles.

Table 1 Proportion of ${ }^{13} \mathrm{C}$ remaining (after 10 days incubation, D10) compared to the amount added at D0

\begin{tabular}{|c|c|c|c|c|}
\hline & \multicolumn{4}{|c|}{$\begin{array}{l}\text { Proportion of }{ }^{13} \mathrm{C} \text { remaining compared to amount added } \\
\text { at D0 }(\%)^{\mathrm{a}}\end{array}$} \\
\hline & \multicolumn{2}{|c|}{$\delta-{ }^{13} \mathrm{C}(\mathrm{AE}-\mathrm{IRMS})$} & \multicolumn{2}{|c|}{${ }^{13}$ C PHE (GC-MS) } \\
\hline & Total soil & DCM extract & Soil residue & DCM extract \\
\hline D0 & $100.0 \pm 6.4$ & $100.0 \pm 7.6$ & $3.5 \pm 0.7$ & $100.0 \pm 9.2$ \\
\hline Bare D10 & $97.8 \pm 6.7$ & $79.9 \pm 10.7$ & $13.0 \pm 0.7$ & $74.3 \pm 1.9$ \\
\hline $\begin{array}{l}\text { Planted } \\
\text { D10 }\end{array}$ & $99.1 \pm 2.3$ & $90.5 \pm 1.2$ & $5.8 \pm 0.2$ & $87.9 \pm 0.9$ \\
\hline \multicolumn{5}{|c|}{$\begin{array}{l}\text { Data based on delta }{ }^{13} \mathrm{C} \text { analyses on total soil, dichloromethane } \\
\text { (DCM) extract and soil residue after extraction measured using AE- } \\
\text { IRMS and on }{ }^{13} \mathrm{C} \text {-phenanthrene (PHE) in dichloromethane extract } \\
\text { measured using GC-MS. }\end{array}$} \\
\hline \multicolumn{5}{|c|}{${ }^{\mathrm{a}}$ values are mean \pm s.e.m. $(n=3)$} \\
\hline
\end{tabular}


After 10 days, this non-extractable fraction reached 13 and $5.8 \%$ in bare and planted microcosms, respectively. This increase likely reflects the incorporation of ${ }^{13} \mathrm{C}$ in microbial biomass and the production of ${ }^{13} \mathrm{C}$-labeled hydrophilic intermediates that were not extracted with DCM. Aerial plant biomass was only weakly enriched in ${ }^{13} \mathrm{C}(0.048 \%$

${ }^{13} \mathrm{C}$ content increase compared to ${ }^{12} \mathrm{C}$-controls).

\section{Taxonomic characterization of active PHE degraders}

Community genomic DNA extracted from ${ }^{12} \mathrm{C}$-controls and ${ }^{13} \mathrm{C}$-SIP incubations was separated by isopycnic centrifugation and fractionated. Quantification of bacterial $16 \mathrm{~S}$ rRNA genes showed a 6-fold increase in fractions 6-8 (buoyant density $1.713-1.727 \mathrm{~g} \mathrm{ml}^{-1}$ ) of ${ }^{13} \mathrm{C}$-SIP bare microcosms compared to ${ }^{12} \mathrm{C}$-controls (Figure S1A). This increase was only 2-fold in planted microcosms (Figure S1B), suggesting a lower incorporation of ${ }^{13} \mathrm{C}$ within bacterial biomass in the presence of ryegrass. Archaeal and fungal rRNA genes were not enriched in any fractions from ${ }^{13} \mathrm{C}$-SIP compared to ${ }^{12} \mathrm{C}$-controls (not shown), suggesting that Archaea and Fungi did not metabolize a significant proportion of PHE in the tested conditions. Fractions 6 to 8

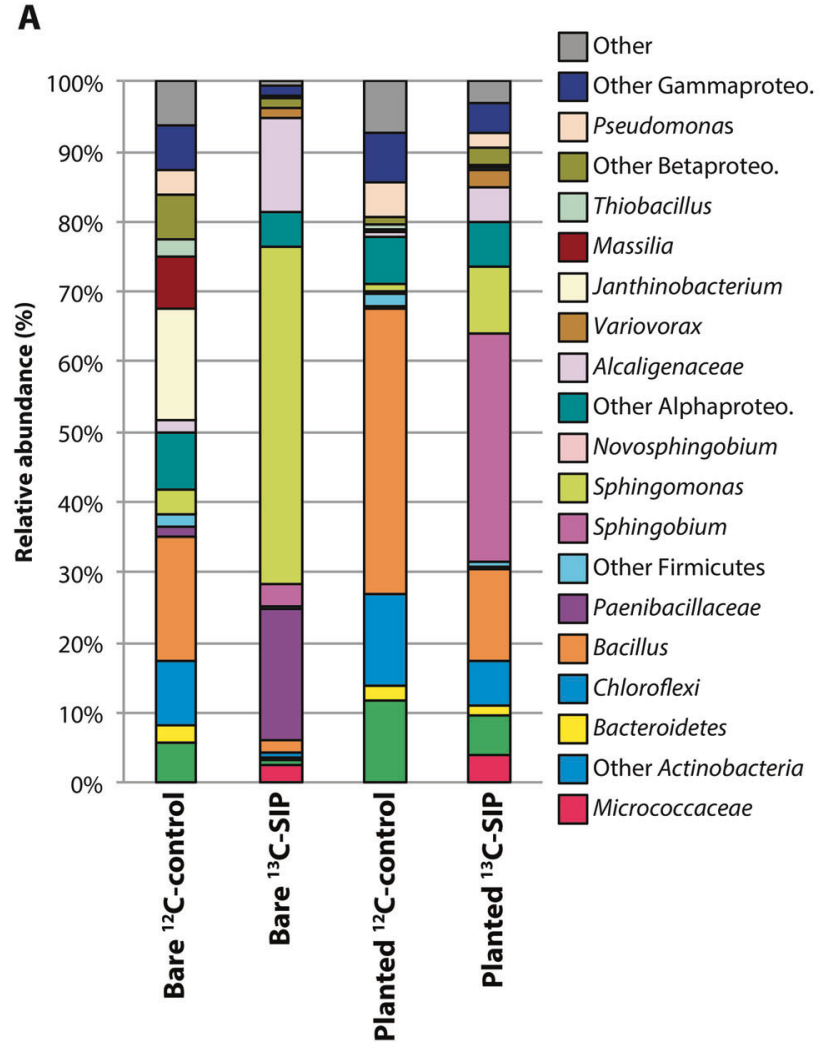

Fig. 1 a Taxonomic profiling of heavy DNA from ${ }^{12} \mathrm{C}$-controls and ${ }^{13} \mathrm{C}$-SIP incubations, in bare or planted microcosms. Values are means of three independent microcosms. b Abundance of taxonomic groups significantly enriched in heavy DNA fractions from ${ }^{13} \mathrm{C}$-SIP from each sample $\left({ }^{13} \mathrm{C}\right.$-SIP and ${ }^{12} \mathrm{C}$-controls $)$ were pooled (hereafter "heavy DNA") and analyzed by high-throughput sequencing of the 16S rRNA genes, using a Heavy-SIP analytical approach [51]. Although other DNA-SIP approaches could have provided a higher sensitivity (i.e. a lower rate of false negatives), Method 2 of the Heavy-SIP approach was predicted to achieve a specificity comparable to HR-SIP and qSIP and largely insensitive to the atom \% excess of DNA and the number of ${ }^{13} \mathrm{C}$-incorporating OTUs $[51,64]$. Combined with the low variation observed between replicates, this ensures a high confidence in the ${ }^{13} \mathrm{C}$-labeled taxa we identified. We obtained a total of 405 345 quality-filtered paired-end 16S rDNA sequences from the 12 samples, ranging from 9532 to 52544 sequences per sample. Based on the rarefied dataset, sequences were clustered in 5690 OTUs at $97 \%$ identity. The taxonomic affiliation of OTUs differed between heavy DNA fractions of ${ }^{13} \mathrm{C}$-SIP incubations and ${ }^{12} \mathrm{C}$-controls in both bare and planted conditions (Fig. 1a). We detected 130 and 73 OTUs significantly enriched in ${ }^{13} \mathrm{C}$-SIP incubations compared to ${ }^{12} \mathrm{C}$-controls in bare and planted conditions, respectively, with 40 OTUs shared between the two conditions (Fig. 1b). These active PHE-degrading OTUs were affiliated to

B

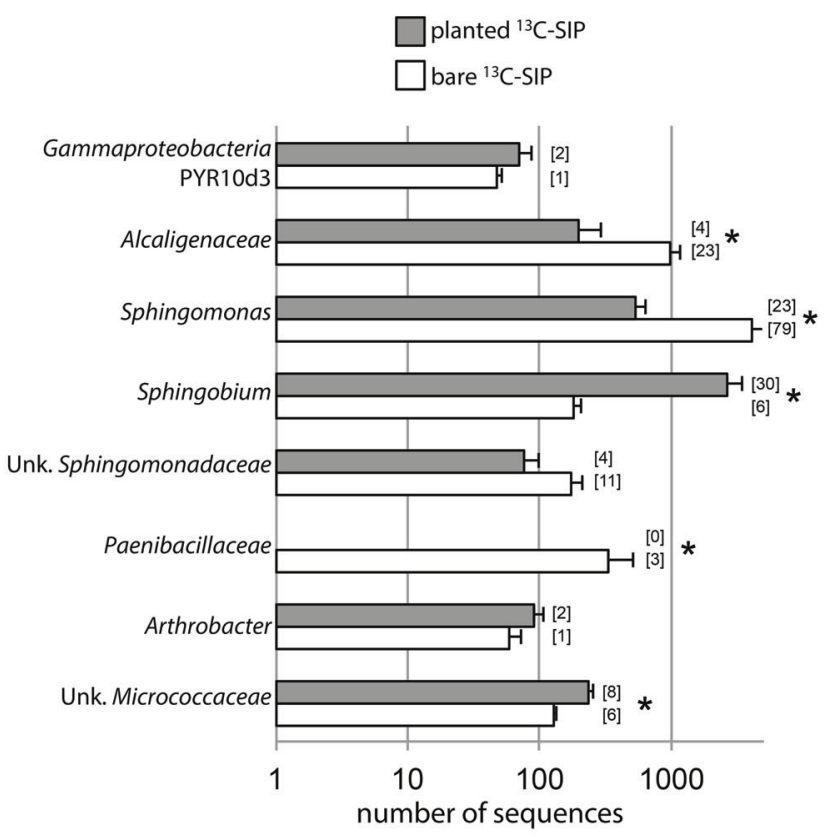

conditions compared to the ${ }^{12} \mathrm{C}$-controls in bare (white) and planted conditions (gray). Values are depicted on a log-scale and are mean \pm s.e.m. $(n=3)$. Values in brackets beside each bar represent the number of OTUs 
Actinobacteria, Alpha-, Beta-, and Gammaproteobacteria in both conditions, while Firmicutes were only enriched in heavy DNA fractions from bare soil. Arthrobacter, unknown Sphingomonadaceae and Gammaproteobacteria "PYR10d3" were present at a similar level in both conditions. PHE-degrading Sphingomonas and Alcaligenaceae OTUs were favored in bare soil compared to planted soil. Conversely, Sphingobium and unknown Micrococcaceae were more represented in planted soil. In each condition, one genus dominated the PHE-degrading population. Namely, Sphingomonas dominated in bare soil $(43 \%$ of total sequences and $61 \%$ of total OTUs), while Sphingobium prevailed in planted soil (28\% of total sequences, $41 \%$ of total OTUs).

\section{Functional profiling of ${ }^{13} \mathrm{C}$-labeled metagenomes}

A total of $\sim 90$ million quality-filtered paired-end reads representing $20 \mathrm{~Gb}$ sequence data were obtained for the six heavy DNA samples from ${ }^{13} \mathrm{C}$-SIP incubations (Table S1). MG-RAST analysis showed that 14 out of 28 functional categories were differentially represented in the two conditions (Fig. 2a). The greatest differences between bare and planted conditions were found for the two categories: "Carbohydrates" (8.63 and $10.61 \%$ in bare and planted soil ${ }^{13} \mathrm{C}$-metagenomes, respectively; $q$-value $\left.=0.016\right)$ and "Metabolism of aromatic compounds" (4.66 and $2.45 \%$ in bare and planted soil ${ }^{13} \mathrm{C}$-metagenomes, respectively; $q$ value $=0.015$ ). Within the category "Carbohydrates" (Fig. 2b), the abundance of gene sequences affiliated to the metabolism of polysaccharides, monosaccharides, fermentation, di- and oligosaccharides, central carbohydrates, and aminosugars, were all significantly over-represented in the planted soil ${ }^{13} \mathrm{C}$-metagenomes. Within the category "Metabolism of aromatic compounds" (Fig. 2c), sequences matching anaerobic degradation genes were detected in identical relative abundance between the two conditions. Genes belonging to the three other sub-categories, i.e. peripheral pathways for catabolism of aromatic compounds, metabolism of central aromatic intermediates, and other, were significantly over-represented in bare soil ${ }^{13} \mathrm{C}$ metagenomes.

Genes encoding enzymes potentially involved in aerobic degradation of aromatic compounds were detected in assembled metagenomes $(12,492$ contigs having a size $>5 \mathrm{~kb})$ using AromaDeg, and their prevalence was calculated relative to the single-copy gene recA (Table 2). A significantly lower prevalence of genes encoding benzoate oxygenases, biphenyl oxygenases, extradiol dioxygenases of the vicinal oxygen chelate superfamily, homoprotocatechuate oxygenases and salicylate oxygenases was found in ${ }^{13} \mathrm{C}$-enriched metagenomes from planted condition compared to bare soil. We further analyzed selected members of two enzyme families involved in the first steps of PAH degradation, namely the biphenyl/naphthalene family of Rieske non-heme iron oxygenases and extradiol dioxygenases of the vicinal oxygen chelate family (EXDO I). The biphenyl/naphthalene family comprises most of the dioxygenases reported to date to activate PAHs for further aerobic degradation, whereas the EXDO I family comprises enzymes that fission the ring of pre-activated mono- or polyaromatic derivatives [58]. We notably detected 66 and 20 open reading frames (ORFs) encoding oxygenases of the biphenyl/naphthalene family from Proteobacteria (Clusters XXIV and XXVI) or Actinobacteria (Clusters I, II, and V), respectively, as well as 46 ORFS encoding proteobacterial EXDOs preferring bicyclic substrates related to dihydroxynaphthalene dioxygenases (Cluster XII). Phylogenetic analysis of biphenyl/naphthalene oxygenases from Proteobacteria (Fig. 3a) revealed that the vast majority (56/66) was closely related to known sequences from Sphingomonas, Sphingobium and Novosphingobium with equal distributions between bare and planted soil. Few additional sequences were related to Cycloclasticus, Burkholderia, or Acidovorax spp. No sequences were affiliated to Pseudomonas. Within Actinobacteria (Fig. 3b), 12 biphenyl/ naphthalene dioxygenases were closely related to sequences from Arthrobacter phenanthrenivorans (Cluster II) and Arthrobacter keyseri (Cluster V). In planted conditions only, four additional sequences related to Mycobacterium and Terrabacter were detected in Cluster V, as well as 2 more divergent sequences. In Cluster XII of the EXDO I family (Fig. 4), most detected sequences (32 out of 46, representing $70 \%$ ) grouped with known proteins from Sphingomonas, Sphingobium and Novosphingobium. Among these, a relatively divergent clade of 20 sequences emerged, with more detected members in bare soil (14 sequences) compared to planted soil. Finally, few additional EXDO I Cluster XII sequences were related to Sphingopyxis, Pseudomonas, Acidovorax or Burkholderia.

\section{Reconstruction of phenanthrene degradation pathways}

Combining results of the above AromaDeg analysis and the GhostKOALA annotation pipeline, we reconstructed both the O-phthalate/protocatechuate pathway leading to the 3-oxoadipate, as well the naphthalene pathway leading to salicylate (Fig. 5; see the complete pathway information on supplemental Figure S2). GhostKOALA failed to recognize genes involved in the first steps of PHE degradation that were detected with AromaDeg, likely because the KEGG database only contains nahAc and nidA genes from Pseudomonas and Mycobacterium, respectively. Salicylate could be converted to gentisate or catechol, being further degraded through ortho- and meta-cleavage pathways leading to intermediates of the 
Fig. 2 Functional analysis of shotgun metagenomic pairedend reads from bare and planted ${ }^{13} \mathrm{C}$-SIP experiments (mean \pm $\mathrm{SD}, n=3$ ) based on subsystem categories in MG-RAST.

Relative abundance of the 28 functional categories (a), the 12 carbohydrate metabolism categories (b), and the 4 categories concerning the metabolism of aromatic compounds (c), with some subcategories shown when significant differences were obtained between bare and planted conditions. Relative abundances were expressed based on the total number of hits provided by MG-RAST analysis, i.e. 5,394,642, $5,631,202$, and $4,264,598$ for triplicates of bare soil metagenomes, and 4,060,525, $5,619,868$, and $4,759,581$ for triplicates of planted soil metagenomes. Asterisks indicate statistically significant differences $(q$-values $<0.05$ after Benjamini-Hochberg correction) between bare and planted conditions
A

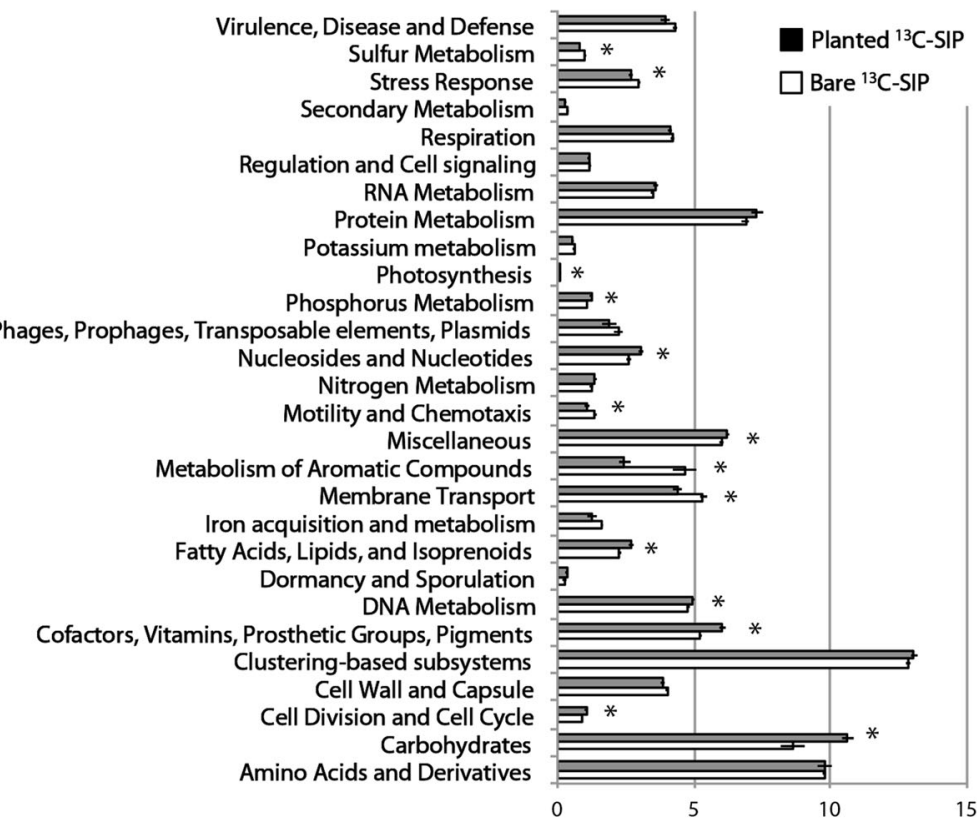

B
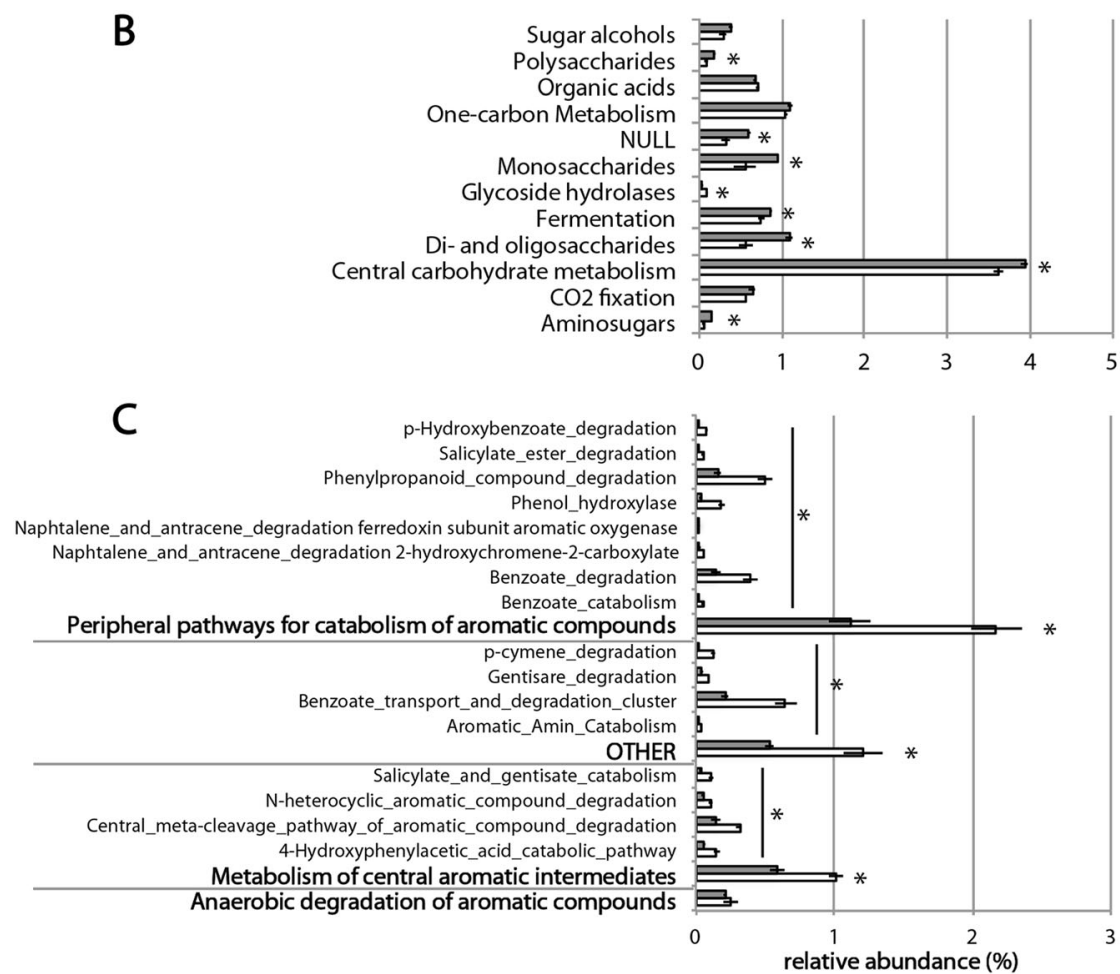

TCA cycle. All genes involved in these pathways were present in both conditions. Sequences affiliated to Sphingomonadales dominated the early steps of degradation leading to 1-hydroxy-2-naphthaldehyde and pyruvate, as well as later reactions converting naphthalene-1,2-diol to salicylaldehyde and pyruvate. Genes involved in the downstream conversion to gentisate were mainly detected from Betaproteobacteria (including
Alcaligenaceae) and Sphingomonadales. Genes annotated in the meta- and ortho-cleavage pathways for catechol utilization were taxonomically more diverse, with sequences affiliated to Alpha-, Beta-, and Gammaproteobacteria, Actinobacteria and Firmicutes. Overall, Actinobacteria and Firmicutes had higher contributions to the phthalate and protocatechuate pathway than to the naphthalene and salicylate pathway. 
Table 2 Normalized prevalence of genes encoding enzymes for aerobic bacterial degradation of aromatics in ${ }^{13} \mathrm{C}$-labeled metagenomes, relative to $r e c A$

\begin{tabular}{llll}
\hline Enzyme class & \multicolumn{3}{l}{ Prevalence relative to recA } \\
\cline { 2 - 4 } & Bare & Planted & $p$-value \\
\hline Benzoate oxygenase & $6.6 \pm 0.9$ & $2.0 \pm 0.2$ & 0.007 \\
Biphenyl/naphthalene oxygenase & $5.2 \pm 0.9$ & $1.8 \pm 0.1$ & 0.018 \\
Extradiol dioxygenase, vicinal oxygen & $6.1 \pm 1.2$ & $2.6 \pm 0.1$ & 0.039 \\
chelate & & & \\
Gentisate oxygenase & $2.3 \pm 0.7$ & $1.2 \pm 0.2$ & 0.171 \\
Homoprotocatechuate oxygenase & $1.0 \pm 0.0$ & $0.5 \pm 0.0$ & 0.001 \\
Protocatechuate oxygenase & $2.0 \pm 0.9$ & $1.0 \pm 0.1$ & 0.304 \\
Phthalate oxygenase & $4.0 \pm 1.5$ & $1.2 \pm 0.0$ & 0.138 \\
Salicylate oxygenase & $7.7 \pm 1.1$ & $2.5 \pm 0.2$ & 0.011 \\
\hline
\end{tabular}

Values are mean \pm s.e.m $(n=3)$, based on features identified using AromaDeg on assembled contigs. The difference between bare and planted condition was tested using Welch's test

\section{Focus on Sphingomonas and Sphingobium metagenomes}

We further focused on the two dominant PHE-degrading populations of Sphingomonas and Sphingobium identified in bare and planted soil through SIP (Fig. 1b). After taxonomic affiliation of contigs larger than $5 \mathrm{~kb}$, the best metagenome assemblies were obtained for the Sphingomonas population in bare soil and the Sphingobium population in planted soil, with maximum contig size larger than $1 \mathrm{Mb}$ (Supplementary Table S2). The Sphingobium metagenome from bare soil was more fragmented (average size $71 \mathrm{~kb}$, maximum size $278 \mathrm{~kb}$ ). The single-copy RecA protein of ${ }^{13} \mathrm{C}$-enriched metagenomes of Sphingomonas was identical in the 3 bare soil microcosms and had its best blastp hit (91\% identity) against Sphingomonas sp. MM-1 [65], while that of Sphingobium was identical in the 3 planted microcosms and had its best blastp hit (100\% identity) against Sphingobium herbicidovorans NBRC 16415 [66] and Sphingobium sp. MI1205 [67]. Functional gene annotation revealed a large arsenal of dioxygenases and monooxygenases with some that could have potential activity on aromatic compounds in Sphingomonas metagenomes from bare soil (Supplementary Table S3), often grouped in genomic regions. The potential for aromatic compounds degradation was much more restricted in Sphingobium metagenomes from planted soil. We then hypothesized that the greater success of Sphingobium PHE-degraders compared to Sphingomonas in planted conditions might not be directly due to aromatic compound catabolism, but rather to a more efficient use of plant-derived carbon sources. To test this hypothesis, we screened the metagenomes for genes encoding carbohydrate active enzymes (CAZymes) in the groups carbohydrate esterases (CE), glycoside hydrolases
(GH) and polysaccharide lyases (PL) (Table 3). Similar numbers of CAZymes were detected in Sphingomonas (3647 total CAZymes) and Sphingobium (46-48 total CAZymes). However, a larger diversity of CAZy families was found in Sphingobium (27 different families) than in Sphingomonas (19-21) metagenomes. Families detected only in Sphingobium metagenomes include enzymes potentially involved in plant cell wall breakdown, including the degradation of xylan (CE6, CE7, GH10, GH115, GH43_12, and GH67), pectin (PL1_2) and other cell wall compounds (GH16), as well as in the use of disaccharides (maltose, trehalose) that are found in root exudates (GH65). Furthermore, the prevalence of three additional families also potentially involved in complex carbohydrate breakdown was higher in Sphingobium metagenomes compared to Sphingomonas (GH13, GH3, PL22).

\section{Discussion}

Phenanthrene is often highly concentrated in PAHcontaminated environments and is a model for research on PAH catabolism [1]. We used DNA-SIP to investigate the diversity and metabolic potential of microorganisms involved in phenanthrene degradation in historically contaminated soil. We further assessed the influence of ryegrass, a plant commonly used in phytoremediation studies on PAH-contaminated soils [2, 11, 68]. To our knowledge, this study is the first to use DNA-SIP combined with metagenomics to assess the influence of plants on bacteria actively involved in phenanthrene degradation in polluted soils. We showed a decreased dissipation of phenanthrene in the ryegrass rhizosphere, corroborating previous results $[12,14]$. The rhizosphere environment is richer in nutrients relative to the surrounding bulk soil due to root exudates, which are comprised of an array of organic compounds such as carbohydrates, amino acids, proteins, flavonoids, aliphatic acids, organic acids, and fatty acids [10, 33]. Excessive nutrient availability can inhibit the biodegradation of pollutants [69-71]. Thus, rhizospheric bacteria may preferentially use labile carbon sources from exudates, leading to slower phenanthrene degradation. Our observations are most relevant to early plant establishment. The impact of plants may be quite different upon maturation. Indeed, there might be a shift between initial negative priming followed by positive priming effect, as previously described [72, 73]. Since rhizosphere processes are dynamic, PAH degradation could be enhanced after a longer period [4]. The phenanthrene losses we observed (20 and $10 \%$ in bare and planted soil in 10 days, respectively) were lower than previous reports, e.g. $68 \%$ in 12 days after addition of concentrated ryegrass root exudates to the same NM soil [14] or $60-70 \%$ in 9 days in slurries of soil from 


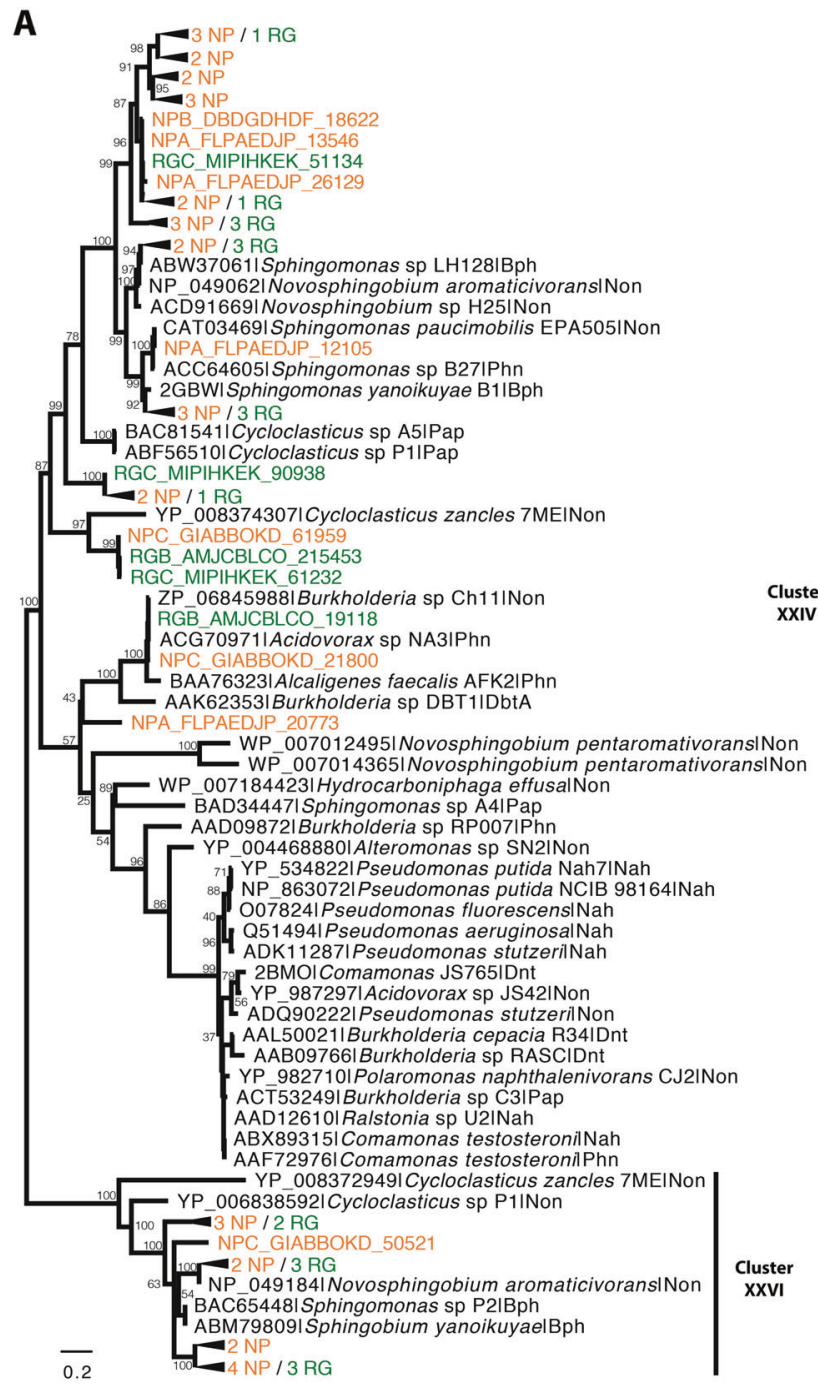

Fig. 3 Maximum-likelihood (ML) phylogenetic reconstructions of dioxygenases (alpha-subunit of Rieske non-heme iron oxygenases) of the biphenyl/naphthalene family from a) Proteobacteria (AromaDeg Clusters XXIV and XXVI) and b) Actinobacteria (Clusters I, II, and $\mathrm{V})$, identified in ${ }^{13} \mathrm{C}$-enriched assembled metagenomes from bare (orange; NPA, NPB, and NPC) and planted (green; RGA, RGB, and RGC) SIP microcosms. Identical sequences were collapsed and numbers of individual sequences in each condition are indicated. Sequences from reference strains are included with their accession

other locations [22, 25]. This discrepancy might partly be due to differences in the initial PHE concentrations (e.g. $1 \mathrm{mg} \mathrm{kg}^{-1}$ in ref. [22], $10 \mathrm{mg} \mathrm{kg}^{-1}$ in ref. [25], $250 \mathrm{mg} \mathrm{kg}^{-1}$ in ref. [14], and the present study). Furthermore, it might be linked to the more realistic conditions of the present experimental setup within a genuine plant rhizosphere, allowing constant input of rhizodeposits during the 10 days time course. The limited dissipation of ${ }^{13} \mathrm{C}-\mathrm{PHE}$ after 10 days minimized the risk of cross-feeding, ensuring reducing potential ${ }^{13} \mathrm{C}$-labeling of microorganisms other than primary degraders of phenanthrene in the NM soil.
B

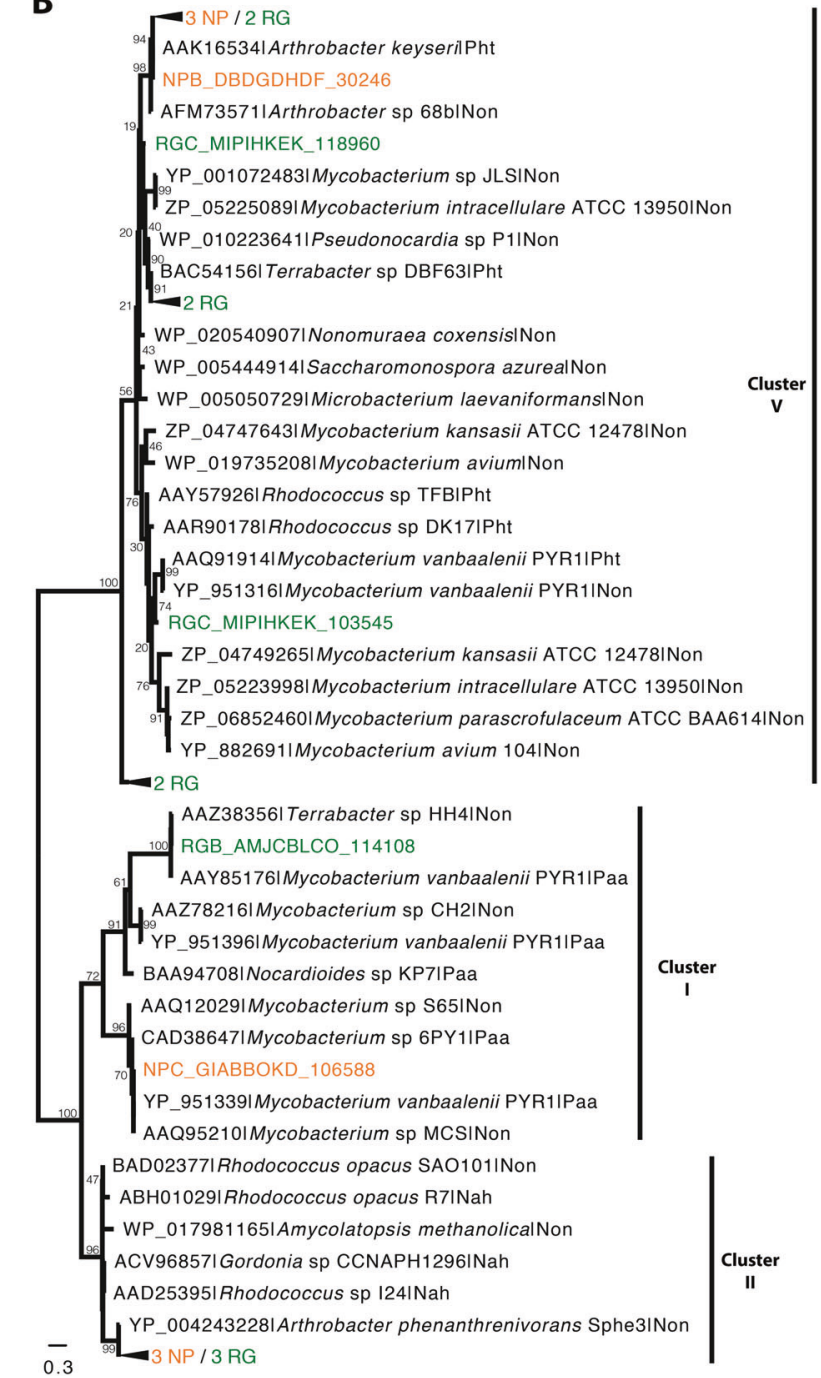

number and experimentally validated substrate (Pht: phthalate; Non: unknown; Paa: polycyclic aromatic hydrocarbons (Actinobacteria); Pap: polycyclic aromatic hydrocarbons (Proteobacteria); Nah: naphthalene; Bph: biphenyl; Phn: phenanthrene; DbtA: dibenzothiophene; Dnt: dinitrotoluene). The $\mathrm{L} G+G+I(G=1.62, I=0.02)$ and $\mathrm{L} G+G$ $(G=0.57)$ substitution models were respectively used for $\mathbf{a}, \mathbf{b})$ after evaluating the best model in MEGA6. ML bootstrap support (100 resamplings) are given. Bars represent fraction of sequence divergence

Similar active ${ }^{13} \mathrm{C}$-PHE-degrading taxa were detected in bare and planted soil, but their relative abundance varied. ${ }^{13} \mathrm{C}$-enriched OTUs affiliated to Arthrobacter, unclassified Sphingomonadaceae and Gammaproteobacteria "PYR10d3" were present at a similar level in both conditions. Members of the Actinobacteria and Sphingomonadaceae are considered potent PAH-degraders in soil and sediments [24, 74-76]. Representatives of the Arthrobacter genus degrade many organic pollutants [77]. Using DNA-SIP, some species were previously shown as the dominant phenanthrene degraders in soil supplemented with root exudates [14] and in activated sludge [27]. Interestingly, an Arthrobacter oxydans strain was 
Fig. 4 Maximum-likelihood (ML) phylogenetic reconstruction of extradiol dioxygenases of the vicinal oxygen chelate family (EXDO I) from AromaDeg Cluster XII, identified in ${ }^{13} \mathrm{C}$-enriched assembled metagenomes from bare (orange; NPA, NPB, and NPC) and planted (green; RGA, RGB, and RGC) SIP microcosms. Identical sequences were collapsed and numbers of individual sequences in each condition are indicated. Sequences from reference strains are included with their accession number and experimentally validated substrate (Dhb: 2,3dihydroxybiphenyl; Dhn: Dihydroxynaphthalene; Dhp: 2,3-Dihydroxybiphenyl and dihydroxylated polycyclic aromatic hydrocarbons (probably dihydroxyphenanthrene); Dhe: 2,3-Dihydroxy-1-ethylbenzene; Thn: 1,2-Dihydroxy-5,6,7, 8tetrahydronaphthalene; DbtC, 2,3-Dihydroxybiphenyl, probably dihydroxydibenzothiophene and dihydroxylated polycyclic aromatic hydrocarbons; Non: unknown). The $\mathrm{L} G+G+I$ substitution model was used $(G=1.09, I=0.09)$ after evaluating the best model in MEGA6. ML bootstrap support (100 re-samplings) are given. The bar represents fraction of sequence divergence

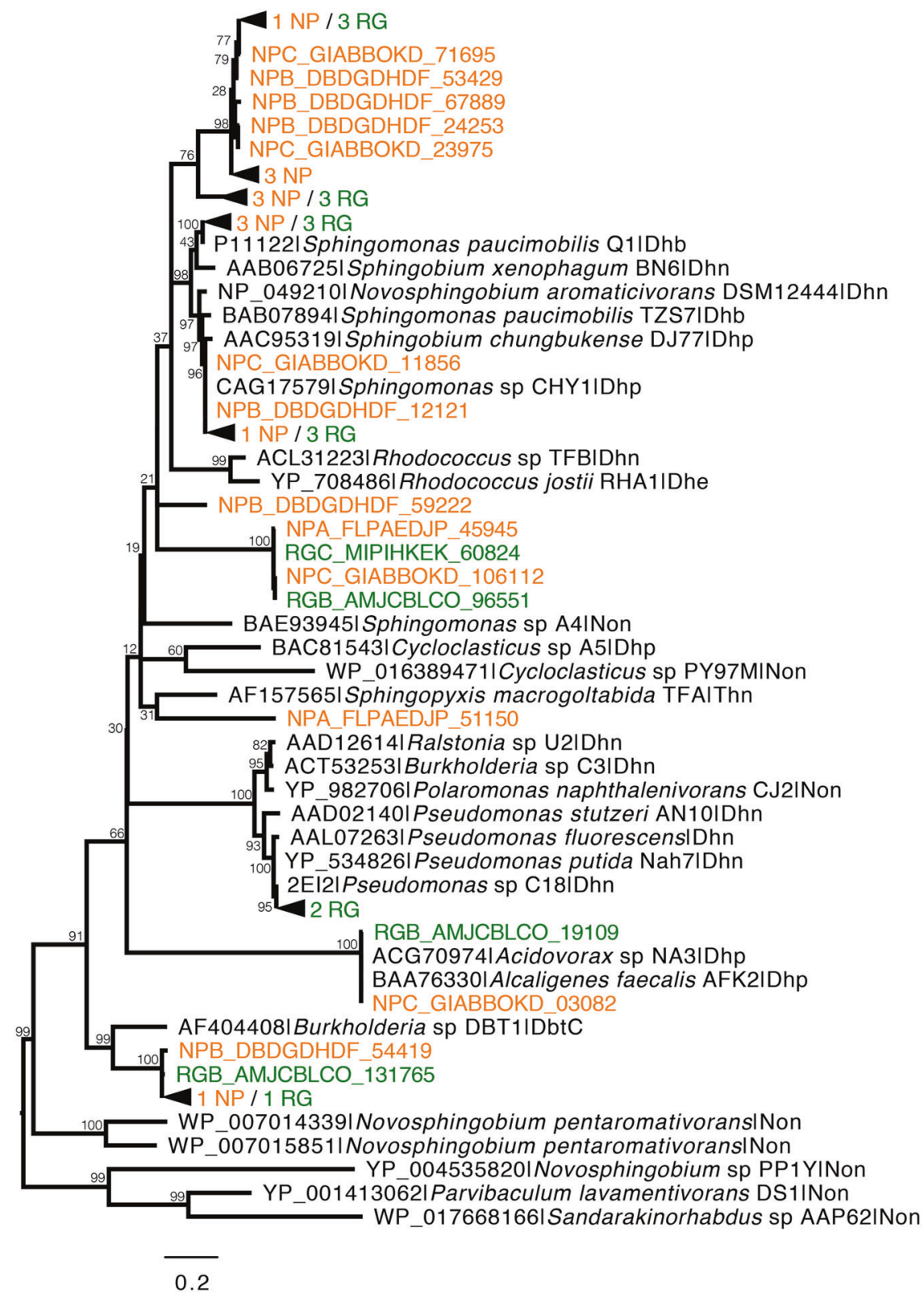

previously isolated from the NM soil for its ability to degrade phenanthrene [78]. The Pyr10d3 candidate order is a separate branch in Gammaproteobacteria originally identified in a SIP experiment using ${ }^{13} \mathrm{C}$-pyrene as substrate [30]. Its abundance increased with higher concentrations of petroleumhydrocarbons in a soil located close to a petrochemical plant [79].

Firmicutes affiliated to Paenibacillaceae were only active in bare soil while a previous study found them as phenanthrene degraders in soil supplemented with root exudates [14]. Paenibacillus spp. were previously enriched from hydrocarbon-contaminated sediment and salt marsh rhizosphere using either naphthalene or phenanthrene as the sole carbon source [80]. Our finding could indicate that
Panibacillaceae members possess various physiological traits allowing adaption to a wide range of ecological niches.

The greatest influence of ryegrass on active PHEdegraders was found for Sphingomonas and Sphingobiumrelated ${ }^{13} \mathrm{C}$-enriched OTUs, which dominated in bare and planted soil, respectively. Although these two genera naturally feature high GC content genomes that would shift the migration of unlabeled DNA towards denser fractions compared to low GC content genomes, they were detected only in low proportions in the sequenced heavy DNA samples (pool of fractions 6-8) of the ${ }^{12} \mathrm{C}$ controls. This suggests that DNA of unlabeled Sphingomonads equilibrated in intermediate fractions (e.g. 


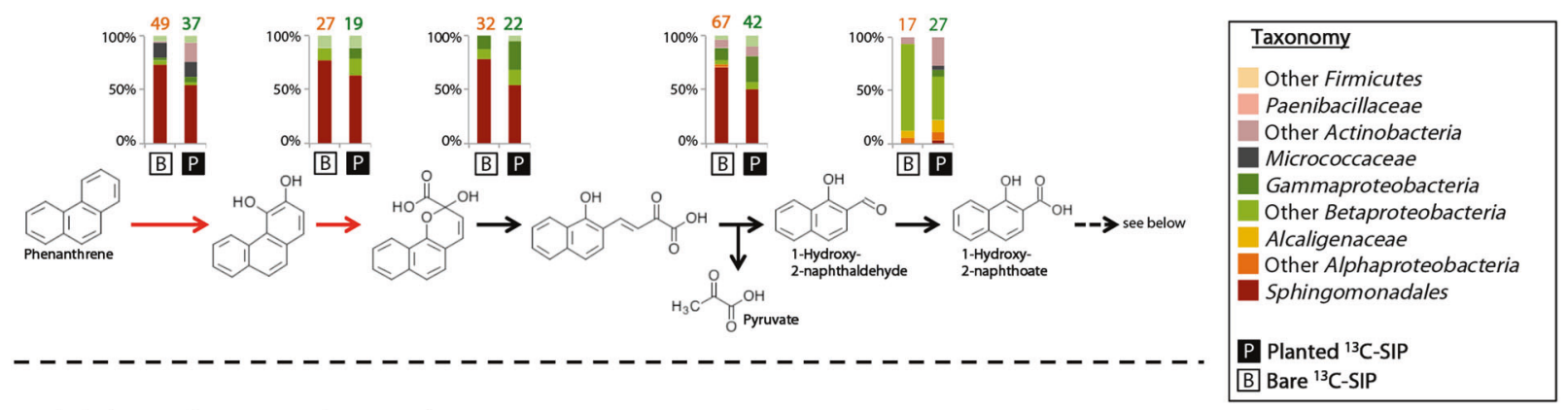

Phthalate and protocatechuate pathway

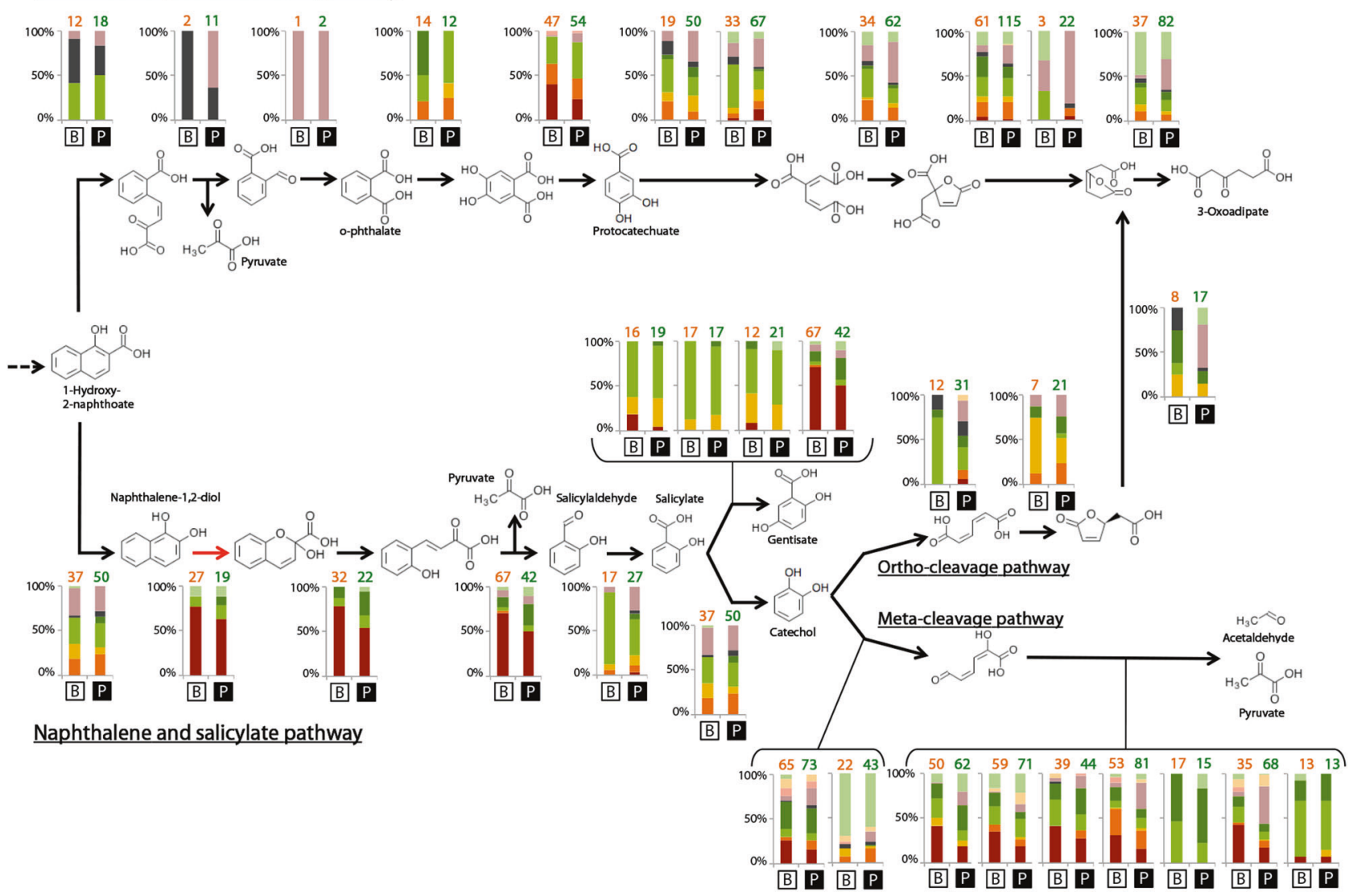

Fig. 5 Reconstruction of phenanthrene metabolic pathways. Red arrows represent genes described in Figs. 3 and 4 and enzyme families described in AromaDeg. Black arrows are genes found in both metagenomes using GhostKOALA (for details about reaction identifiers with enzyme names, EC number, gene names and identification numbers of each reaction see the supplementary Figure S2). The

fractions 9-10), preventing bias in the detection of a significant enrichment in ${ }^{13} \mathrm{C}$-SIP incubations. Members of the Sphingomonads, belonging to the Sphingomonadaceae family within the Alphaproteobacteria, are known to utilize both substituted and unsubstituted mono- and poly-aromatic hydrocarbons with up to 5 rings [28] and have been widely identified as phenanthrene degraders [25, 81]. PAH-degrading sphingomonads are common Gram-negative, aerobic, chemoheterotroph bacteria adapted to oligotrophic environments [81]. They have number of genes identified in the two conditions is added in orange (bare ${ }^{13} \mathrm{C}$-SIP: B) and green (planted ${ }^{13} \mathrm{C}$-SIP: P) above bar graphs with the taxonomic affiliation of identified genes. Note that $32.1 \%$ $(114,211 / 355,456)$ and $29.8 \%(225,994 / 758,006)$ of the entries could be assigned to known functions for bare and planted ${ }^{13} \mathrm{C}$-SIP metagenomes, respectively

evolved original strategies to enhance PAH bioavailability, e.g. hydrophobic and negatively charged cell surface, production of a specific sphingoglycolipid, formation of biofilms due to sphingans exopolysaccharide production, presence of high-affinity uptake system, and chemotactic response towards PAH [81]. Sphingomonas spp. are commonly encountered in PAH-contaminated environments as phenanthrene degraders $[11,23,24,74$, 81-85] and the amount of phenanthrene available in soils influences the diversity of Sphingomonas [74]. Similarly, 
Table 3 Detection of genes encoding putative carbohydrate active enzymes (CAZymes)

\begin{tabular}{|c|c|c|c|c|c|c|c|}
\hline \multirow{3}{*}{$\begin{array}{l}\text { CAZY family } \\
\mathrm{CE} 1\end{array}$} & \multicolumn{6}{|c|}{$\begin{array}{l}\text { Counts based on dbcan annotation in }{ }^{13} \mathrm{C} \text {-enriched } \\
\text { metagenomes }\end{array}$} & \multirow{3}{*}{$\begin{array}{l}\text { Example of known activities in family } \\
\text { Xylanase }\end{array}$} \\
\hline & \multicolumn{3}{|c|}{$\begin{array}{l}\text { Sphingomonas in bare } \\
\text { soil }\end{array}$} & \multicolumn{3}{|c|}{$\begin{array}{l}\text { Sphingobium in } \\
\text { planted soil }\end{array}$} & \\
\hline & 6 & 6 & 5 & 4 & 4 & 4 & \\
\hline CE14 & 0 & 0 & 0 & 1 & 1 & 1 & Diacetylchitobiose deacetylase \\
\hline CE3 & 2 & 2 & 0 & 2 & 2 & 2 & Acetyl xylan esterase \\
\hline CE4 & 4 & 4 & 3 & 1 & 1 & 1 & $\begin{array}{l}\text { Chitooligosaccharide deacetylase, peptidoglycan } N \text { - } \\
\text { acetylglucosamine deacetylase, acetyl xylan esterase }\end{array}$ \\
\hline CE6 & 0 & 0 & 0 & 1 & 1 & 1 & Acetyl xylan esterase \\
\hline CE7 & 0 & 0 & 0 & 1 & 1 & 1 & Acetyl xylan esterase \\
\hline GH1 & 3 & 4 & 3 & 0 & 0 & 0 & $\beta$-glucosidases, $\beta$-galactosidases \\
\hline GH10 & 0 & 0 & 0 & 1 & 1 & 1 & Endo-xylanase \\
\hline GH102 & 2 & 1 & 1 & 1 & 1 & 1 & Peptidoglycan lytic transglycosylase \\
\hline GH103 & 2 & 2 & 1 & 1 & 1 & 1 & Peptidoglycan lytic transglycosylase \\
\hline GH108 & 1 & 1 & 1 & 1 & 1 & 1 & $\mathrm{~N}$-acetylmuramidase \\
\hline GH109 & 2 & 2 & 2 & 2 & 2 & 1 & $\alpha-N$-acetylgalactosaminidase \\
\hline GH115 & 0 & 0 & 0 & 2 & 2 & 2 & Xylan $\alpha$-1,2-glucuronidase \\
\hline GH13 & 1 & 1 & 1 & 3 & 3 & 3 & $\alpha$-glucosidase \\
\hline GH130 & 2 & 2 & 2 & 0 & 0 & 0 & $\beta$-1,4-mannosylglucose phosphorylase \\
\hline GH136 & 0 & 0 & 0 & 1 & 1 & 1 & Lacto- $N$-biosidase \\
\hline GH15 & 1 & 1 & 1 & 1 & 1 & 1 & Exolytic glucoamylase \\
\hline GH16 & 0 & 0 & 0 & 2 & 2 & 2 & Wide variety of activities on $\beta-1,4$ or $\beta-1,3$ glycosidic bonds \\
\hline $\mathrm{GH} 23$ & 5 & 7 & 6 & 5 & 4 & 4 & Peptidoglycan lyases \\
\hline $\mathrm{GH} 24$ & 2 & 0 & 1 & 0 & 0 & 0 & Lysozyme \\
\hline $\mathrm{GH} 25$ & 0 & 0 & 0 & 1 & 1 & 1 & Lysozyme \\
\hline GH28 & 1 & 1 & 1 & 0 & 0 & 0 & Polygalacturonases \\
\hline $\mathrm{GH} 3$ & 1 & 1 & 1 & 4 & 4 & 4 & $\begin{array}{l}\beta \text {-D-glucosidases, } \alpha \text {-L-arabinofuranosidases, } \beta \text {-D- } \\
\text { xylopyranosidases, } N \text {-acetyl- } \beta \text {-D-glucosaminidases }\end{array}$ \\
\hline GH43_12 & 0 & 0 & 0 & 1 & 1 & 1 & Endo- $\beta-1,4$-xylanase / $\alpha$-L-arabinofuranosidase \\
\hline GH5 & 4 & 4 & 0 & 0 & 0 & 0 & Endoglucanase, endomannanase \\
\hline GH65 & 0 & 0 & 0 & 1 & 1 & 1 & $\begin{array}{l}\text { Maltose phosphorylase, trehalose phosphorylase, kojibiose } \\
\text { phosphorylase, and trehalose 6-phosphate phosphorylase }\end{array}$ \\
\hline GH67 & 0 & 0 & 0 & 1 & 1 & 1 & Xylan $\alpha$-1,2-glucuronidase \\
\hline GH73 & 0 & 0 & 1 & 0 & 0 & 0 & Lysozyme \\
\hline GH74 & 2 & 2 & 1 & 0 & 0 & 0 & Xyloglucanase \\
\hline GH76 & 1 & 1 & 0 & 0 & 0 & 0 & $\alpha-1,6$-mannanase \\
\hline PL1_2 & 0 & 0 & 0 & 2 & 2 & 2 & Pectin/pectate lyase \\
\hline PL12 & 1 & 1 & 1 & 1 & 1 & 1 & Heparin-sulfate lyase \\
\hline PL15_2 & 0 & 0 & 0 & 1 & 1 & 1 & Alginate lyase \\
\hline PL22 & 2 & 2 & 2 & 5 & 5 & 5 & Oligogalacturonate lyase \\
\hline PL6 & 2 & 2 & 2 & 1 & 1 & 1 & Alginate lyase, chondroitinase $\mathrm{B}$ \\
\hline Total families & 21 & 20 & 19 & 27 & 27 & 27 & \\
\hline $\begin{array}{l}\text { Total } \\
\text { CAZymes }\end{array}$ & 47 & 47 & 36 & 48 & 47 & 46 & \\
\hline
\end{tabular}

$\overline{\mathrm{CE}}, \mathrm{GH}$, and PL in ${ }^{13} \mathrm{C}$-enriched metagenomes from Sphingomonas and Sphingobium in bare and planted SIP incubations, respectively. Counts are given for the three independent replicates.

$C E$ carbohydrate esterase, $G H$ glycoside hydrolase, $P L$ polysaccharide lyase 
representatives of Sphingobium can degrade environmental pollutants such as PAHs [86-89].

In bare soil, ${ }^{13} \mathrm{C}$-enriched Sphingomonas OTUs coincided with a greater proportion of active Alcaligenaceae OTUs, while in rhizospheric soil Sphingobium OTUs coincided with Micrococcaceae. Alcaligenes representatives were previously identified during bioremediation of creosote-contaminated soil [90], and many studies showed PAH degradation by various Alcaligenes isolates [91-93]. Micrococcaceae are well known PAH degraders [94, 95] and their abundance was favored in planted compared to bare aged-PAH contaminated soil [35].

To date, the impact of plant rhizosphere on functional diversity was mostly assessed in pristine soils [96, 97]. Our study is the first to highlight the differences in metagenomes of PAH-degrading bacteria from bulk and rhizospheric soil in polluted environments. The ${ }^{13} \mathrm{C}$-enriched metagenomes from planted soil showed that ryegrass rhizosphere selected for an active population with specific functions compared to bare soil, i.e. a lower proportion of genes involved in aromatic compound utilization together with a higher and diversified capability for carbohydrate degradation. This confirms our first hypothesis that root exudates would favor the development of PAH-degrading bacteria with specific functional traits at the genome level. Here, the presence of ryegrass benefits bacteria that are able to use a larger diversity of carbon sources including carbohydrates from exudates. This is reminiscent of the higher transcription of genes related to carbon and amino acid utilization shown in the willow rhizosphere [98]. Moreover, the AromaDeg analysis confirmed the lower proportion of genes potentially involved in the first steps of aerobic degradation of aromatic compounds in planted soil metagenomes.

We further hypothesized that the PAH-degrading microbial guild is composed of diverse bacteria possessing complete catabolic pathways and acting in parallel. Reconstruction of complete catabolic pathways (Fig. 5) showed that several routes are used to mineralize phenanthrene both in bare and planted soil, since genes assigned to the o-phthalate/protocatechuate, gentisate and catechol ortho- and meta-cleavage pathways were detected. Our data further revealed that the complete mineralization of phenanthrene is achieved through combined activity of taxonomically diverse co-occurring bacteria, acting sequentially rather than in parallel. Hence, active PHEdegrading communities act as consortia. This strategy might limit the competition for substrates between different degrading populations and overall increase PAH dissipation efficiency. Previous studies reported synergistic effects and enhancement of PAH degradation for bacterial consortia compared to pure cultures, potentially due to individual strains having complementary degradation pathways [99]. Construction of consortia by mixing several known
PAH-degraders has failed to maximize cooperation among different species [100], indicating a common genomic evolution among partners of the consortia. This bacterial cooperative mutualism was recently demonstrated between 2 mutant strains of Pseudomonas putida having incomplete but complementary toluene degradation pathways, resulting in a cross-feeding consortium [101]. Our findings fit the Black Queen theory [102] in which one individual produces a by-product that will enhance the fitness of other individuals able to use that product [103]. This novel view on PAH-degradation processes, based on bacterial interactions and metabolic cooperation, opens up new perspectives in microbial ecology.

Within the consortium, Sphingomonadales were the major taxa performing the first steps of phenanthrene degradation. They appear to degrade phenanthrene preferentially through the lower meta-cleavage pathway, as previously shown for Sphingobium chungbukense [104]. These results suggest that autochthonous Sphingomonadales could play a critical role to initiate in-situ PAH remediation in historically polluted soils by increasing PAH bioavailability and opening new substrate niches for other members of the consortium. The dominant PHE-degraders Sphingomonas and Sphingobium OTUs were active both in bare and planted soils but in different proportions (Fig. 1b), leading to a lower phenanthrene degradation rate in the rhizosphere where Sphingobium dominated. Previous studies did not evidence a specificity of Sphingomonas and Sphingobium spp. for environments with low and high nutrient levels, respectively. For example, Vinas et al. [90] detected Sphingomonas in soil bioremediation treatments both with and without nutrient amendment. Recently, comparative genomics of Novosphingobium strains showed that phylogenetic relationships were less likely to describe functional similarities in metabolic traits, than the habitats from which they were isolated [105]. Thus, catabolic differences among Sphingomonads appear strain-specific. Some Sphingomonad strains can utilize various mono-, oligo-, and polysaccharides [81, 106] rather than being specialists in the degradation of aromatic compounds. The greater success of ${ }^{13} \mathrm{C}$-enriched Sphingobium OTUs in planted soil, together with a larger diversity of CAZymes than the Sphingomonas metagenome from bare soil, suggests a similar behavior. In the conditions tested, PHEdegrading Sphingobium representatives likely took advantage of labile carbon compounds from root exudates, outcompeting the less versatile PHE-degrading Sphingomonas.

\section{Conclusion}

Improving soil PAH-rhizoremediation strategies depends on a better understanding of the factors involved in the 
variability of rhizospheric processes. Microbial diversity, activity and metabolism are key parameters that control PAH-degradation. This study showed that active phenanthrene degraders are diverse in aged-polluted soil and could act as a cooperative consortium whereby different taxa perform successive metabolic steps. Members of the Sphingomonadales were the dominant PHE-degraders identified through DNA-SIP, and the main actors of the first steps in the degradation pathways. Hence, they likely play a crucial role to initiate in-situ PAH remediation. Plant establishment, at least initially, reduces PAH degradation compared to bare soil due to differences in the PAH degrading bacterial consortia and their associated metabolic pathways. In particular, plants induced a drastic shift in the taxonomic composition of PHE-degrading Sphingomonadales, favouring the growth of Sphingobium populations with a more diverse repertoire of carbohydrate-active enzymes potentially targeting plant root material, to the detriment of less versatile Sphingomonas representatives that prevailed in bare soil. These findings pave the way for future studies of soils featuring contrasting physicochemical characteristics, origin, and pollution history, as well as other plant species to deepen our comprehension of microbial cooperative interactions needed for organic pollutant degradation.

Acknowledgements This study was part of the RhizOrg project funded by the ANR (Agence Nationale de la Recherche, ANR-13-JSV70007_01 project allocated to A.C.). We thank Dr. S. Uroz (Labex Arbre, INRA Champenoux) for giving them access to the ultracentrifuge equipment, Dr. E. Morin (INRA Champenoux) for initial discussions on metagenome assembly, the ABiMS platform (Roscoff) where metagenomic analyses were performed, and Dr. E. Ficko-Blean for critical reading of the manuscript.

\section{Compliance with ethical standards}

Conflict of interest The authors declare that they have no conflict of interest.

Publisher's note: Springer Nature remains neutral with regard to jurisdictional claims in published maps and institutional affiliations.

\section{References}

1. Ghosal D, Ghosh S, Dutta TK, Ahn Y. Current state of knowledge in microbial degradation of polycyclic aromatic hydrocarbons (PAHs): a review. Front Microbiol. 2016;7:1369.

2. Khan S, Afzal M, Iqbal S, Khan QM. Plant-bacteria partnerships for the remediation of hydrocarbon contaminated soils. Chemosphere. 2013;90:1317-32.

3. Doyle E, Muckian L, Hickey AM, Clipson N. Microbial PAH degradation. Adv Appl Microbiol. 2008;65:27-66.

4. Reilley KA, Banks MK, Schwab AP. Dissipation of polycyclic aromatic hydrocarbons in the rhizosphere. J Environ Qual. 1996;25:212-9.
5. Binet P, Portal JM, Leyval C. Dissipation of 3-6-ring polycyclic aromatic hydrocarbons in the rhizosphere of ryegrass. Soil Biol Biochem. 2000;32:2011-7.

6. Chaudhry Q, Blom-Zandstra M, Gupta SK, Joner E. Utilising the synergy between plants and rhizosphere microorganisms to enhance breakdown of organic pollutants in the environment. Environ Sci Pollut Res. 2005;12:34-48.

7. El Amrani A, Dumas AS, Wick LY, Yergeau E, Berthomé R. "Omics" insights into PAH degradation toward improved green remediation biotechnologies. Environ Sci Technol. 2015;49:11281-91.

8. Rentz JA, Alvarez PJ, Schnoor JL. Repression of Pseudomonas putida phenanthrene-degrading activity by plant root extracts and exudates. Environ Microbiol. 2004;6:574-83.

9. Phillips LA, Greer CW, Farrell RE, Germida JJ. Plant root exudates impact the hydrocarbon degradation potential of a weathered-hydrocarbon contaminated soil. Appl Soil Ecol. 2012;52:56-64.

10. Berg G, Smalla K. Plant species and soil type cooperatively shape the structure and function of microbial communities in the rhizosphere. FEMS Microbiol Ecol. 2009;68:1-13.

11. Guo M, Gong Z, Miao R, Rookes J, Cahill D, Zhuang J. Microbial mechanisms controlling the rhizosphere effect of ryegrass on degradation of polycyclic aromatic hydrocarbons in an aged-contaminated agricultural soil. Soil Biol Biochem. 2017;113:130-42.

12. Thomas F, Cébron A. Short-term rhizosphere effect on available carbon sources phenanthrene degradation and active microbiome in an aged-contaminated industrial soil. Front Microbiol. 2016;7:92.

13. Olson PE, Castro A, Joern M, DuTeau NM, Pilon-Smits EA, Reardon KF. Comparison of plant families in a greenhouse phytoremediation study on an aged polycyclic aromatic hydrocarbon-contaminated soil. J Environ Qual. 2007;36:1461.

14. Cébron A, Louvel B, Faure P, France-Lanord C, Chen Y, Murrell JC, et al. Root exudates modify bacterial diversity of phenanthrene degraders in PAH-polluted soil but not phenanthrene degradation rates. Environ Microbiol. 2011;13:722-36.

15. Sul WJ, Park J, Quensen JF, Rodrigues JL, Seliger L, Tsoi TV, et al. DNA-stable isotope probing integrated with metagenomics for retrieval of biphenyl dioxygenase genes from polychlorinated biphenyl-contaminated river sediment. Appl Environ Microbiol. 2009; 75:5501-6.

16. Kim SJ, Park SJ, Cha IT, Min D, Kim JS, Chung WH, et al. Metabolic versatility of toluene-degrading iron-reducing bacteria in tidal flat sediment characterized by stable isotope probing-based metagenomic analysis. Environ Microbiol. 2014;16:189-204.

17. Dombrowski N, Donaho JA, Gutierrez T, Seitz KW, Teske AP, Baker BJ. Reconstructing metabolic pathways of hydrocarbondegrading bacteria from the Deepwater Horizon oil spill. Nat Microbiol. 2016;1:16057.

18. Jeon CO, Park W, Padmanabhan P, DeRito C, Snape JR, Madsen EL. Discovery of a bacterium with distinctive dioxygenase that is responsible for in situ biodegradation in contaminated sediment. Proc Natl Acad Sci USA. 2003;100:13591-6.

19. Singleton DR, Powell SN, Sangaiah R, Gold A, Ball LM, Aitken MD. Stable-isotope probing of bacteria capable of degrading salicylate naphthalene or phenanthrene in a bioreactor treating contaminated soil. Appl Environ Microbiol. 2005;71:1202-9.

20. Padmanabhan P, Padmanabhan S, DeRito C, Gray A, Gannon D, Snape JR, et al. Respiration of ${ }^{13} \mathrm{C}$-labeled substrates added to soil in the field and subsequent $16 \mathrm{~S}$ rRNA gene analysis of ${ }^{13} \mathrm{C}$ labeled soil DNA. Appl Environ Microbiol. 2003;69:1614-22.

21. Uhlik O, Wald J, Strejcek M, Musilova L, Ridl J, Hroudova M, et al. Identification of bacteria utilizing biphenyl benzoate and 
naphthalene in long-term contaminated soil. PLoS ONE. 2012;7: e40653.

22. Jiang L, Song M, Luo C, Zhang D, Zhang G. Novel phenanthrene-degrading bacteria identified by DNA-stable isotope probing. PLoS ONE. 2015;10:e0130846.

23. Martin F, Torelli S, Le Paslier D, Barbance A, Martin-Laurent F, Bru D, et al. Betaproteobacteria dominance and diversity shifts in the bacterial community of a PAH-contaminated soil exposed to phenanthrene. Environ Pollut. 2012;162:345-53.

24. Regonne RK, Martin F, Mbawala A, Ngassoum MB, Jouanneau Y. Identification of soil bacteria able to degrade phenanthrene bound to a hydrophobic sorbent in situ. Environ Pollut. 2013;180:145-51.

25. Song M, Jiang L, Zhang D, Luo C, Wang Y, Yu Z, et al. Bacteria capable of degrading anthracene phenanthrene and fluoranthene as revealed by DNA based stable-isotope probing in a forest soil. J Hazard Mater. 2016;308:50-57.

26. Crampon M, Cébron A, Portet-Koltalo F, Uroz S, Le Derf F, Bodilis J. Low effect of phenanthrene bioaccessibility on its biodegradation in diffusely contaminated soil. Environ Pollut. 2017;225:663-73.

27. Li J, Zhang D, Song M, Jiang L, Wang Y, Luo C, et al. Novel bacteria capable of degrading phenanthrene in activated sludge revealed by stable-isotope probing coupled with high-throughput sequencing. Biodegradation. 2017;28:423-36.

28. Jones MD, Crandell DW, Singleton DR, Aitken MD. Stableisotope probing of the polycyclic aromatic hydrocarbondegrading bacterial guild in a contaminated soil. Environ Microbiol. 2011;13:2623-32.

29. Zhang S, Wang Q, Xie S. Stable isotope probing identifies anthracene degraders under methanogenic conditions. Biodegradation. 2012;23:221-30.

30. Singleton DR, Sangaiah R, Gold A, Ball LM, Aitken MD. Identification and quantification of uncultivated Proteobacteria associated with pyrene degradation in a bioreactor treating PAHcontaminated soil. Environ Microbiol. 2006;8:1736-45.

31. Jones MD, Singleton DR, Carstensen DP, Powell SN, Swanson JS, Pfaender FK, et al. Effect of incubation conditions on the enrichment of pyrene-degrading bacteria identified by stableisotope probing in an aged PAH-contaminated soil. Microb Ecol. 2008;56:341-9.

32. Song M, Luo C, Jiang L, Zhang D, Wang Y, Zhang G. Identification of benzo [a] pyrene $(\mathrm{BaP})$-metabolizing bacteria in forest soils using DNA-based stable-isotope probing. Appl Environ Microbiol. 2015;81:7368-76.

33. el Zahar Haichar F, Marol C, Berge O, Rangel-Castro JI, Prosser JI, Balesdent J, et al. Plant host habitat and root exudates shape soil bacterial community structure. ISME J. 2008;2:1221.

34. Pett-Ridge J, Firestone MK. Using stable isotopes to explore root-microbe-mineral interactions in soil. Rhizosphere. 2017;3:244-53.

35. Cébron A, Beguiristain T, Faure P, Norini M-P, Masfaraud J-F, Leyval C. Influence of vegetation on the in situ bacterial community and polycyclic aromatic hydrocarbon $(\mathrm{PAH})$ degraders in aged PAH-contaminated or thermal-desorption-treated soil. Appl Environ Microbiol. 2009;75:6322-30.

36. Biache C, Mansuy-Huault L, Faure P, Munier-Lamy C, Leyval C. Effects of thermal desorption on the composition of two coking plant soils: impact on solvent extractable organic compounds and metal bioavailability. Environ Pollut. 2008;156:671-7.

37. Biache C, Ouali S, Cébron A, Lorgeoux C, Colombano S, Faure $\mathrm{P}$. Bioremediation of PAH-contamined soils: consequences on formation and degradation of polar-polycyclic aromatic compounds and microbial community abundance. J Hazard Mater. 2017;329:1-10.
38. Dunford E, Neufeld JD. DNA stable-isotope probing (DNASIP). J Vis Exp. 2010;2:1-6.

39. Felske A, Akkermans ADL, De Vos WM. Quantification of $16 \mathrm{~S}$ rRNAs in complex bacterial communities by multiple competitive reverse transcription-PCR in temperature gradient gel electrophoresis fingerprints. Appl Environ Microbiol. 1998;64:4581-7.

40. Baker GC, Smith JJ, Cowan DA. Review and re-analysis of domain-specific $16 \mathrm{~S}$ primers. J Microbiol Methods. 2003;55:541-55.

41. Smit E, Smit E, Leeflang P, Leeflang P, Glandorf B, Glandorf B, et al. Analysis of fungal diversity in the wheat rhizosphere by sequencing of cloned PCR-Amplied genes encoding 18S rRNA and temperature gradient gel electrophoresis. Appl Environ Microbiol. 1999;65:2614-21.

42. Vainio EJ, Hantula J. Direct analysis of wood-inhabiting fungi using denaturing gradient gel electrophoresis of amplified ribosomal DNA. Mycol Res. 2000;104:927-36.

43. Cébron A, Norini M-P, Beguiristain T, Leyval C. Real-Time PCR quantification of PAH-ring hydroxylating dioxygenase (PAH-RHD $\alpha$ ) genes from Gram positive and Gram negative bacteria in soil and sediment samples. J Microbiol Methods. 2008;73:148-59.

44. Kozich JJ, Westcott SL, Baxter NT, Highlander SK, Schloss PD. Development of a dual-index sequencing strategy and curation pipeline for analyzing amplicon sequence data on the MiSeq Illumina sequencing platform. Appl Environ Microbiol. 2013;79:5112-20.

45. Masella AP, Bartram AK, Truszkowski JM, Brown DG, Neufeld JD. PANDAseq: paired-end assembler for Illumina sequences. BMC Bioinform. 2012;13:31.

46. Caporaso JG, Kuczynski J, Stombaugh J, Bittinger K, Bushman FD, Costello EK, et al. QIIME allows analysis of highthroughput community sequencing data. Nat Methods. 2010;7:335-6.

47. Edgar RC. Search and clustering orders of magnitude faster than BLAST. Bioinformatics. 2010;26:2460-1.

48. Edgar RC, Haas BJ, Clemente JC, Quince C, Knight R. UCHIME improves sensitivity and speed of chimera detection. Bioinformatics. 2011;27:2194-200.

49. Wang Q, Garrity GM, Tiedje JM, Cole JR. Naive Bayesian classifier for rapid assignment of rRNA sequences into the new bacterial taxonomy. Appl Environ Microbiol. 2007;73:5261-7.

50. McDonald D, Price MN, Goodrich J, Nawrocki EP, DeSantis TZ, Probst A, et al. An improved Greengenes taxonomy with explicit ranks for ecological and evolutionary analyses of bacteria and archaea. ISME J. 2012;6:610-8.

51. Youngblut ND, Barnett SE, Buckley DH. SIPSim: a modeling toolkit to predict accuracy and aid design of DNA-SIP experiments. Front Microbiol. 2018;9:570.

52. R Core Team. R: A Language and Environment for Statistical Computing. R Foundation for Statistical Computing, Vienna, Austria, 2013.

53. Bolger AM, Lohse M, Usadel B. Trimmomatic: a flexible trimmer for Illumina sequence data. Bioinformatics. 2014;30:2114-20.

54. Meyer F, Paarmann D, D'Souza M, et al. The metagenomics RAST server-a public resource for the automatic phylo- genetic and functional analysis of metagenomes. BMC Bioinform. 2008;9:386.

55. Bankevich A, Nurk S, Antipov D, Gurevich AA, Dvorkin M, Kulikov AS, et al. SPAdes: a new genome assembly algorithm and its applications to single-cell sequencing. J Comput Biol. 2012;19:455-77.

56. Patil KR, Roune L, McHardy AC. The phyloPythiaS web server for taxonomic assignment of metagenome sequences. PLoS One. 2012; 7:e38581. 
57. Seemann T. Prokka: rapid prokaryotic genome annotation. Bioinformatics. 2014;30:2068-9.

58. Duarte M, Jauregui R, Vilchez-Vargas R, Junca H, Pieper DH. AromaDeg a novel database for phylogenomics of aerobic bacterial degradation of aromatics. Database. 2014;2014:1-12.

59. Katoh K, Rozewicki J, Yamada KD. MAFFT online service: multiple sequence alignment interactive sequence choice and visualization. Brief Bioinform. 2017;bbx108:1-7.

60. Waterhouse AM, Procter JB, Martin DMA, Clamp M, Barton GJ. Jalview Version 2-A multiple sequence alignment editor and analysis workbench. Bioinformatics. 2009;25:1189-91.

61. Tamura K, Stecher G, Peterson D, Filipski A, Kumar S. MEGA6: molecular evolutionary genetics analysis version 6.0. Mol Biol Evol. 2013;30:2725-9.

62. Yin Y, Mao X, Yang J, Chen X, Mao F, Xu Y. DbCAN: a web resource for automated carbohydrate-active enzyme annotation. Nucleic Acids Res. 2012;40:445-51.

63. Kanehisa M, Sato Y, Morishima K. BlastKOALA and GhostKOALA: KEGG tools for functional characterization of genome and metagenome sequences. J Mol Biol. 2016;428:726-31.

64. Hungate BA, Mau RL, Schwartz E, Caporaso JG, Dijkstra P, van Gestel N, et al. Quantitative microbial ecology through stable isotope probing. Appl Environ Microbiol. 2015;81:7570-81.

65. Tabata M, Ohtsubo Y, Ohhata S, Tsuda M, Nagata Y. Complete genome sequence of the $\gamma$-hexachlorocyclohexane-degrading bacterium Sphingomonas sp strain MM-1. Genome Announc. 2013;1:e00247-13.

66. Zipper C, Nickel K, Angst W, Kohler HP. Complete microbial degradation of both enantiomers of the chiral herbicide mecoprop [(RS)-2-(4-chloro-2-methylphenoxy) propionic acid] in an enantioselective manner by Sphingomonas herbicidovorans sp. nov. Appl Environ Microbiol. 1996;62:4318-22.

67. Tabata M, Ohhata S, Nikawadori Y, Sato, TKishida K, Ohtsubo $\mathrm{Y}$, et al. Complete genome sequence of a $\gamma$ hexachlorocyclohexane-degrading bacterium Sphingobium sp strain MI1205. Genome Announc. 2016;4:e00246-16.

68. Rezek J, Mackova M, Zadrazil F, Macek T. The effect of ryegrass (Lolium perenne) on decrease of PAH content in long term contaminated soil. Chemosphere. 2008;70:1603-8.

69. Chaillan F, Chaineau CH, Point V, Saliot A, Oudot J. Factors inhibiting bioremediation of soil contaminated with weathered oils and drill cuttings. Environ Pollut. 2006;144:255-65.

70. Carmichael LM, Pfaender FK. The effect of inorganic and organic supplements on the microbial degradation of phenanthrene and pyrene in soils. Biodegradation. 1997;8:1-13.

71. Chaineau CH, Rougeux G, Yepremian C, Oudot J. Effects of nutrient concentration on the biodegradation of crude oil and associated microbial populations in the soil. Soil Biol Biochem. 2005;37:1490-7.

72. Kuzyakov Y, Friedel JK, Stahr K. Review of mechanisms and quantification of priming effects. Soil Biol Biochem. 2000;32:1485-98.

73. Dijkstra FA, Carrillo Y, Pendall E, Morgan JA. Rhizosphere priming: a nutrient perspective. Front Microbiol. 2013;4:216.

74. Leys NM, Ryngaert A, Bastiaens L, Verstraete W, Top EM, Springael D. Occurrence and phylogenetic diversity of Sphingomonas strains in soils contaminated with polycyclic aromatic hydrocarbons. Appl Environ Microbiol. 2004;70:1944-55.

75. Leys NM, Bastiaens L, Verstraete W, Springael D. Influence of the carbon/nitrogen/phosphorus ratio on polycyclic aromatic hydrocarbon degradation by Mycobacterium and Sphingomonas in soil. Appl Microbiol Biotechnol. 2005;66:726-36.

76. Alonso-Gutiérrez J, Figueras A, Albaigés J, Jiménez N, Vinas M, Solanas AM, et al. Bacterial communities from shoreline environments (Costa da Morte Northwestern Spain) affected by the Prestige oil spill. Appl Environ Microbiol. 2009;75:3407-18.
77. Leigh MB, Pellizari VH, Uhlík O, Sutka R, Rodrigues J, Ostrom $\mathrm{NE}$, et al. Biphenyl-utilizing bacteria and their functional genes in a pine root zone contaminated with polychlorinated biphenyls (PCBs). ISME J. 2007;1:134.

78. Thion C, Cébron A, Beguiristain T, Leyval C. PAH biotransformation and sorption by Fusarium solani and Arthrobacter oxydans isolated from a polluted soil in axenic cultures and mixed co-cultures. Int Biodeter Biodegrad. 2012;68:28-35.

79. Tardif S, Yergeau É, Tremblay J, Legendre P, Whyte LG, Greer $\mathrm{CW}$. The willow microbiome is influenced by soil petroleumhydrocarbon concentration with plant compartment-specific effects. Front Microbiol. 2016;7:1363.

80. Daane LL, Harjono I, Barns SM, Launen LA, Palleron NJ, Häggblom MM. PAH-degradation by Paenibacillus spp and description of Paenibacillus naphthalenovorans sp nov a naphthalene-degrading bacterium from the rhizosphere of salt marsh plants. Int J Syst Evol Microbiol. 2002;52:131-9.

81. Waigi MG, Kang F, Goikavi C, Ling W, Gao Y. Phenanthrene biodegradation by sphingomonads and its application in the contaminated soils and sediments: a review. Int Biodeter Biodegrad. 2015;104:333-49.

82. Daane LL, Harjono I, Zylstra GJ, Häggblom MM. Isolation and characterization of polycyclic aromatic hydrocarbon-degrading bacteria associated with the rhizosphere of salt marsh plants. Appl Environ Microbiol. 2001;67:2683-91.

83. Johnsen AR, Winding A, Karlson U, Roslev P. Linking of microorganisms to phenanthrene metabolism in soil by analysis of ${ }^{13}$ C-labeled cell lipids. Appl Environ Microbiol. 2002;68:6106-13.

84. Meyer S, Moser R, Neef A, Stahl U, Kämpfer P. Differential detection of key enzymes of polyaromatic-hydrocarbondegrading bacteria using PCR and gene probes. Microbiology. 1999;145:1731-41.

85. Ding GC, Heuer H, Smalla K. Dynamics of bacterial communities in two unpolluted soils after spiking with phenanthrene: soil type specific and common responders. Front Microbiol. 2012;3:290.

86. Kanaly RA, Harayama S. Biodegradation of high-molecularweight polycyclic aromatic hydrocarbons by bacteria. J Bacteriol. 2000;182:2059-67.

87. Kanaly RA, Harayama S. Advances in the field of high-molecular-weight polycyclic aromatic hydrocarbon biodegradation by bacteria. Microb Biotechnol. 2010;3:136-64.

88. Stolz A. Molecular characteristics of xenobiotic-degrading sphingomonads. Appl Microbiol Biotechnol. 2009;81:793-811.

89. Maeda AH, Kunihiro M, Ozeki Y, Nogi Y, Kanaly RA. Sphingobium barthaii sp nov a high molecular weight polycyclic aromatic hydrocarbon-degrading bacterium isolated from cattle pasture soil. Int J Syst Evol Microbiol. 2015;65:2919-24.

90. Vinas M, Sabaté J, Espuny MJ, Solanas AM. Bacterial community dynamics and polycyclic aromatic hydrocarbon degradation during bioremediation of heavily creosote-contaminated soil. Appl Environ Microbiol. 2005;71:7008-18.

91. Weissenfels WD, Beyer M, Klein J. Degradation of phenanthrene fluorene and fluoranthene by pure bacterial cultures. Appl Microbiol Biotechnol. 1990;32:479-84.

92. Lal B, Khanna S. Degradation of crude oil by Acinetobacter calcoaceticus and Alcaligenes odorans. J Appl Bacteriol. 1996;81:355-62.

93. Samanta SK, Singh OV, Jain RK. Polycyclic aromatic hydrocarbons: environmental pollution and bioremediation. Trends Biotechnol. 2002;20:243-8.

94. Kästner M, Breuer-Jammali M, Mahro B. Enumeration and characterization of the soil microflora from hydrocarbon-contaminated soil sites able to mineralize polycyclic aromatic hydrocarbons (PAH). Appl Microbiol Biotechnol. 1994;41:267-73. 
95. Margesin R, Moertelmaier C, Mair J. Low-temperature biodegradation of petroleum hydrocarbons (n-alkanes phenol anthracene pyrene) by four actinobacterial strains. Int Biodeter Biodegrad. 2013;84:185-91.

96. Uroz S, Ioannidis P, Lengelle J, Cébron A, Morin E, Buée M, et al. Functional assays and metagenomic analyses reveals differences between the microbial communities inhabiting the soil horizons of a Norway spruce plantation. PLoS ONE. 2013;8:e55929.

97. Mendes LW, Kuramae EE, Navarrete AA, Van Veen JA, Tsai SM. Taxonomical and functional microbial community selection in soybean rhizosphere. ISME J. 2014;8:1577.

98. Yergeau E, Sanschagrin S, Maynard C, St-Arnaud M, Greer CW. Microbial expression profiles in the rhizosphere of willows depend on soil contamination. ISME J. 2014;8:344.

99. Wang Z, Zhang J, Zhang Y, Hesham AL, Yang M. Molecular characterization of a bacterial consortium enriched from an oilfield that degrades phenanthrene. Biotechnol Lett. 2006;28:617-21.

100. Ghazali FM, Rahman RNZA, Salleh AB, Basri M. Biodegradation of hydrocarbons in soil by microbial consortium. Int Biodeter Biodegrad. 2004;54:61-67.
101. Tecon R, Or D. Cooperation in carbon source degradation shapes spatial self-organization of microbial consortia on hydrated surfaces. Sci Rep. 2017;7:43726.

102. Morris JJ, Lenski RE, Zinser ER. The Black Queen Hypothesis: evolution of dependencies through adaptive gene loss. MBio. 2012;3:e00036-12.

103. Sachs JL, Hollowell AC. The origins of cooperative bacterial communities. MBio. 2012;3:e00099-12.

104. Lee SY, Sekhon SS, Ban YH, Ahn JY, Ko JH, Lee L, et al. Proteomic analysis of polycyclic aromatic hydrocarbons (PAHs) degradation and detoxification in Sphingobium chungbukense. J Microbiol Biotechnol. 2016;26:1943-50.

105. Kumar R, Verma H, Haider S, Bajaj A, Sood U, Ponnusamy K, et al. Comparative genomic analysis reveals habitat-specific genes and regulatory hubs within the genus Novosphingobium. MSystems. 2017;2:e0020-17.

106. Tao XQ, Lu GN, Dang Z, Yang C, Yi XY. A phenanthrenedegrading strain Sphingomonas sp. GY2B isolated from contaminated soils. Process Biochem. 2007;42:401-8. 